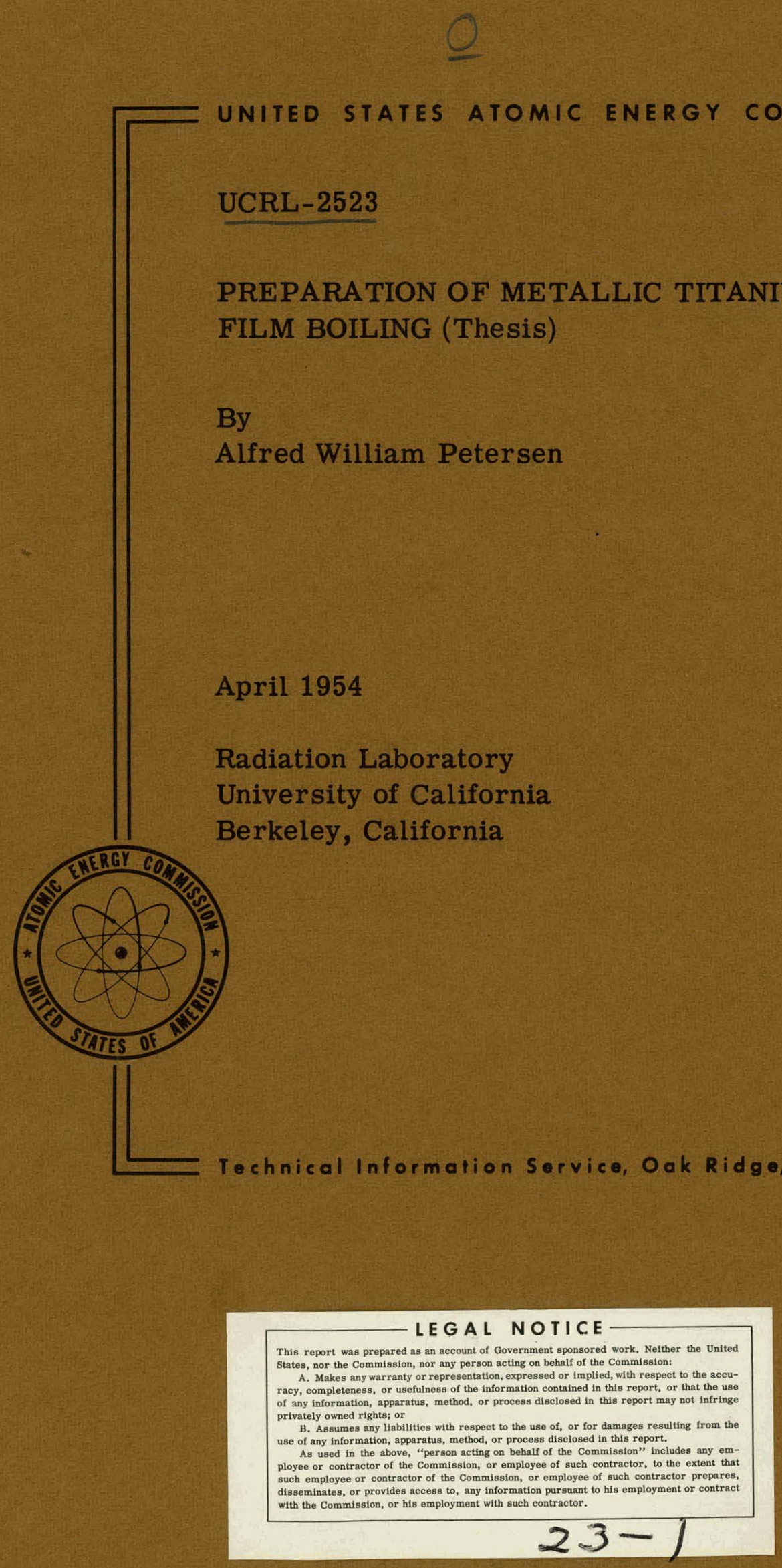




\section{DISCLAIMER}

This report was prepared as an account of work sponsored by an agency of the United States Government. Neither the United States Government nor any agency Thereof, nor any of their employees, makes any warranty, express or implied, or assumes any legal liability or responsibility for the accuracy, completeness, or usefulness of any information, apparatus, product, or process disclosed, or represents that its use would not infringe privately owned rights. Reference herein to any specific commercial product, process, or service by trade name, trademark, manufacturer, or otherwise does not necessarily constitute or imply its endorsement, recommendation, or favoring by the United States Government or any agency thereof. The views and opinions of authors expressed herein do not necessarily state or reflect those of the United States Government or any agency thereof. 


\section{DISCLAIMER}

Portions of this document may be illegible in electronic image products. Images are produced from the best available original document. 
Subject Category, CHEMISTRY.

Work performed under Contract No. W-7405-eng-48.

Issuance of this document does not constitute authority for declassification of classified material of the same or similar content and title by the same author.

This report has been reproduced with minimum alteration directly from manuscript provided the Technical Information Service in an effort to expedite availability of the information contained herein.

Since nontechnical and nonessential prefatory material has been deleted, the first page of the report is page 5 . Reproduction of this information is encouraged by the United States Atomic Energy Commission. Arrangements for your republication of this document in whole or in part should be made with the author and the organization he represents.

Printed in USA, Price 45 cents. Available from the Office of Technical Services, Department of Commerce, WashIngton 25, D. C. 


\section{ABSTRACI}

The Van Arkel-deBoer method for producing ductile titanium by thermal decomposition of $\mathrm{PII}_{4}$ vapor and deposition on an electrically heated filament is modified by film boiling $\mathrm{TiI}_{4}$ liquid on a heated filament, resulting in similar titanium deposition on the filament and liberation of iodine to the gaseous phase. The increase of deposition rate from $10.100 \mathrm{mg} / \mathrm{cm}^{2}-h r$ for the Van Arkel process to $1000-10,000 \mathrm{mg} / \mathrm{cm}^{2}-\mathrm{hr}$ decreases the energy input from $40.90 \mathrm{Kw}-\mathrm{hr} / \mathrm{Ib}$ $\mathrm{Ti}^{\mathrm{S}}$ for the Van Arkel process to $2-20 \mathrm{KW}-\mathrm{hr} / \mathrm{lb} \mathrm{Ti}$ by the film boiling method. 


\section{PAGES 2 to 4 WERE INTENTIONALLY LEFT BLANK}


PREPARATION OF IETALIIC TITANITU BY FILM BOILING

Alfred William Petersen

Radiation Laboratory and

Department of Chemistry and Chemical Engineering

April, 1954

I. ABSTRACT

The Van Arkel-deBoer method for producing ductile titanium by thermal decomposition of $\mathrm{TiI}_{4}$ vapor and deposition on an electrically heated filament is modified by film boiling TiI $_{4}$ liquid on a heated filament, resulting in similar titanium deposition on the filament and liberation of iodine to the gaseous phase. The increase of deposition rate from $10-100 \mathrm{mg} / \mathrm{cm}^{2}-\mathrm{hr}$ for the Van Arkel process to $1000-10,000 \mathrm{mg} / \mathrm{cm}^{2}-\mathrm{hr}$ decreases the energy input from $40-90 \mathrm{KW}-\mathrm{hr} / \mathrm{lb}$ $\mathrm{Ti}^{8}$ for the Van Arkel process to $2-20 \mathrm{Kw}-\mathrm{hr} / \mathrm{lb} \mathrm{Ti}$ by the film boiling method. 


\section{INTRODUCTION}

This dissertation is concerned with the production of titanium of 99.9\% purity, called "ductile titanium", by a modification of the Van Arkel-deBoer ${ }^{2}$ method, which is now in use commercially. In this method, an electrically heated wire is suspended from two electrodes, which are placed in container holding titanium tetraiodide vapor at a vapos pressure not exceeding $37 \mathrm{~mm} \mathrm{Hg}_{0}{ }^{15}$ The vapor diffuses to the hot wire, usually maintained at $1100-1600^{\circ} \mathrm{C}_{9}^{7.5}$ and decomposes accoralng to the reaction

$$
\mathrm{TII}_{4} \longrightarrow \mathrm{TI}+4 \mathrm{I}_{0}
$$

liberating gaseous atomic iodine and depositing solid, crystalline titanium on the wire. The liberated iodine diffuses to a heated source of crude $\mathrm{Ti}$ and reacts to form more $\mathrm{Ti}_{4}$ vapor, which again diffuses to the hot wire and completes the cyclic process.

The above process may be modified by suspending the hot wire in liquid $\mathrm{TiI}_{4}$, instead of the rapor, and obtaining film boiling. This type of boiling is characterized by the formation of a continuous film of vapor over the wire surface. Since only vapor contacts the wire surface, the temperature of this surface may be raised as high as desirable, within the limit of mechanical strength requirements for the wire. By properly setting the input voltage, the temperature of the wire may be maintained above $1100^{\circ} \mathrm{C}$, and by evacuating the vessel holding the liquid $\mathrm{FiI}_{4}$ and mintaining a suitable condenser temperas ture, the vapor pressure of $\mathrm{TI}_{4}$ mag be held below $37 \mathrm{~mm}$ Hg. Thus, the conditions of operation of the Van Arkel-deBoer method may be obtained with film boiling; and hence, it is postulated that "ductile 


\section{$-3$}

titanium" may be produced by this method。

The purpose of this thesis is to prove the above postulate by experiment and to ascertain the approximate power input, rate of : deposition of $\mathrm{Ti}$, and purity. A larger film boiling apparatus will be designed for further work, in order to obtain more precise conditions of operation. 
III. PREPARATION OF TITANIUM TETRAIODIDE

There are many methods available for the preparation of titanium tetraiodide. A summary of a number of these methods follows:

(1) The direct reaction of iodine vapor and heated titanium was used by Fast, "Hautefeuille, and Moissan. 11 A glass container was evacuated and the titanium heated to a high temperature. The titanium was cooled to $180^{\circ} \mathrm{C}$ and Lodine was Introduced Into the container. The spontaneous reaction produced titanium tetraiodide, which condensed in a cooled bulb attached to the container. The tetraiodide was purified by sublimation to remove the excess iodine.

(2) Hautefeuille $e^{9}$ passed dry hydrogen iodide through warm titanium tetrachloride. The temperature was gradually raised to the boiling point of titanium tetrachloride. Repeated sublimation through a stream of hydrogen purified the tetraiodide.

(3) Hautefeuilie $e^{9}$ passed a mixture of iodine vapor, titanium tetrachloride vapor, and hydrogen through a tube heated to a dull red. The titanium tetraiodide formed was purified as in method (2)。

(4) Hoch and Knauff ${ }^{10}$ made titanium tetraiodide by the methathesis of titanium tetrachloride and phosphorus trifodide.

(5) Pascal ${ }^{12}$ reacted titanium carbide and iodine. According to Blumenthal and $\operatorname{smith}^{4}$ this reaction is low in efficiency.

(6) A promising method for commercial application was proposed by Blumenthal and Smitho ${ }^{4}$ Metallic titanium was reacted with iodine dissolved in carbon disulfide by heating the mixture to boiling and refluxing until the reaction was complete. A water bath maintained at $80^{\circ} \mathrm{C}$ was used to distill off the carbon disulfide; increasing the temperature by direct heating removed axy exsess iodine; finally; pure 


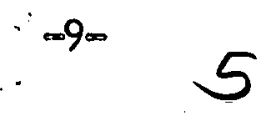

$\mathrm{TiI}_{4}$ was distilled off from any solids remaining in the reaction mixture. This is a desirable method, because the reaction occurs at the boiling point of carbon disulfide; there are no corrosion problems normally found with hot iodine vapors on the gasket materials; the iodine not used for making $\mathrm{TiI}_{4}$ is easily recovered; the carbon disulfide from the distillation step is ready to be used again; and a very impure titanium alloy may be used as the starting material.

(7) The method actually used to prepare $\mathrm{TiI}_{4}$ for the work in this thesis is described below:

Refer to Figure 1 for the apparatus. $I_{2}$ crystals were added to the $500 \mathrm{ml}$ flask, and the air condenser was fitted into place. The $\mathrm{I}_{2}$ was melted with a Bunsen burner, and a few grams of Ti sponge were added to the flask through the top of the condenser. Heating was continued in order to form $I_{2}$ vapor on the pieces of sponge, since liquid $I_{2}$ and $T i$ do not react rapidiy。 This initiated the reaction,

$$
\mathrm{Ti}+2 \mathrm{I}_{2}(\mathrm{~g}) \longrightarrow \mathrm{TiI}_{4}(\mathrm{~g})_{9}
$$

which, although exothermic, i's not explosive due to the limited surface area on the sponge. The pieces of sponge rose to the liquid surface and continued reacting until they, were used up; the heat of reaction maintained an envelope of vaporized $\mathrm{I}_{2}$ and $\mathrm{TiI}_{4}$ around them, providing. a constant source of $\mathrm{I}_{2}$ vapor. The heat was dissipated through the condenser and reactor walls, liquefying the vapors and allowing the liquid reflux to return to the reaction mixture. When the reaction subsided, another increment of sponge was added through the top of the condenser. The above process was repeated until no further reaction occurred, due to the decrease in free $I_{2}$ concentration in the reaction mixture. The excess $I_{2}$, which was usually 5-15 weight 
$-10-$

6.

3

PREPARATION OF $\mathrm{TII}_{4}$

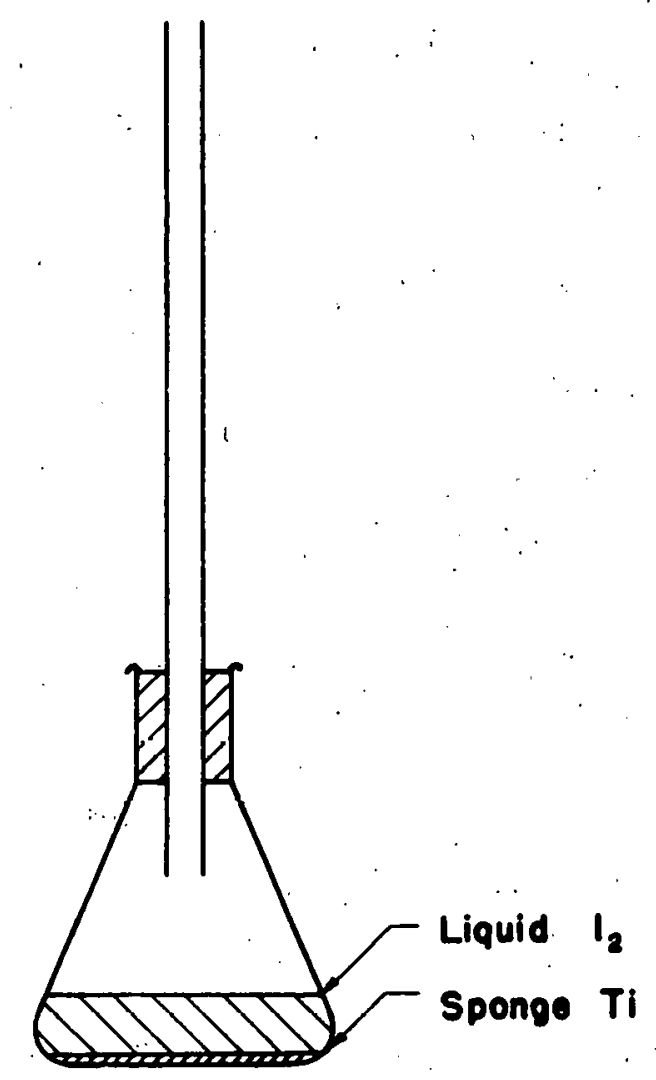

T18. 1

$23-8$ 


\section{7}

percent of the reaction mixture, was removed by simple distillation at atmospheric pressure. The $\mathrm{TiI}_{4}$ fraction boiling above $365^{\circ} \mathrm{C}$ (normal boiling point is $377^{\circ} \mathrm{C}$ ) was next distilled of $\mathrm{f}$ and collected for use; any non-volatile titanium oxides or nitrides formed during the reaction remained in the distillation flask.

There are a few disadvantages to this method of preparation. Large increments of titanium sponge should not be added unless the heat of reaction $\left(-131 \mathrm{kcal} . / \mathrm{mole}^{\mathrm{TiI}}{ }_{4}\right)$ can be safely dissipated by the condenser and reactor walls. The reaction was difficult to control, because once the violent exothermic reaction was initiated, it did not stop until all of the sponge was used up. With the condenser open to the atmosphere, titanium oxides formed, lowering the yield of $\mathrm{TiI}_{4}$; water vapor from the atmosphere formed $\mathrm{HI}$ from $\mathrm{TiI}_{4}$, lowering the yield with respect to iodine. The vapors are corrosive to most common gasket and construction materials.

The advantages of this method are the simplicity of the apparatus and the rapidity of the direct reaction of $T i$ and $I_{2}$. 
IV. FIIM BOILING ON SHORT WIRES

\section{Apparatus}

The apparatus shown in Figure 2, Page 13, is for film boiling TiI 4 on short wire filaments. The current to the filament is supplied through a bank of three $5 \mathrm{KVA}$ transformers connected in parallel; they decrease the 230-volt line by a factor of four to 57.5 volts. The current is controlled by adjusting the voltage over a $0-67.5$ volt range with a 7 KVA variable transformer on the low-voltage side of the bank of transformers. The current is measured directly by a Weston AC ammeter, and the total voltage drop across the electrodes is measured" with a Weston AC voltmeter. The sealed-in-glass tungsten electrodes are hard soldered to the filament for the film boiling of $\mathrm{TiI}_{4}$. The top part of the reactor, holding the electrodes, is connected to the reactor by a ground glass joint, which is lubricated with silicone grease. The bottom part of the reactor, containing $\mathrm{TiI}_{4}$, is wrapped with nichrome heating wires to maintain the TiI $_{4}$ in the liquid state. To this bottom part is attached an air condenser for liquefying or solidifying the $\mathrm{TiI}_{4}$ vapors produced bo boiling. ... An ice or liquid-

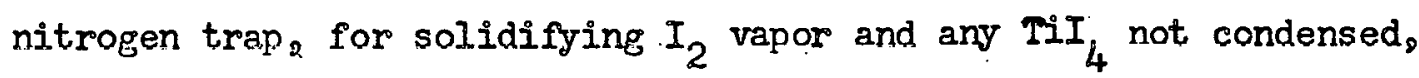
is attached to the low-pressure side of the air condenser。 Finally, a "Megavac" mechanical vacuum pump is attached to the trap, for evacuating the system to a fow $\mathrm{mm}$ Hg.

\section{Procedure}

A 0.010 -inch-diameter tungsten filament was hard soldered to the tungsten electrodes. $\mathrm{TiI}_{4}$ was melted ( $\mathrm{mP} 14^{\circ} \mathrm{C}$ ) and poured into the reactor chamber; the top of the reactor chamber, containing the 
9

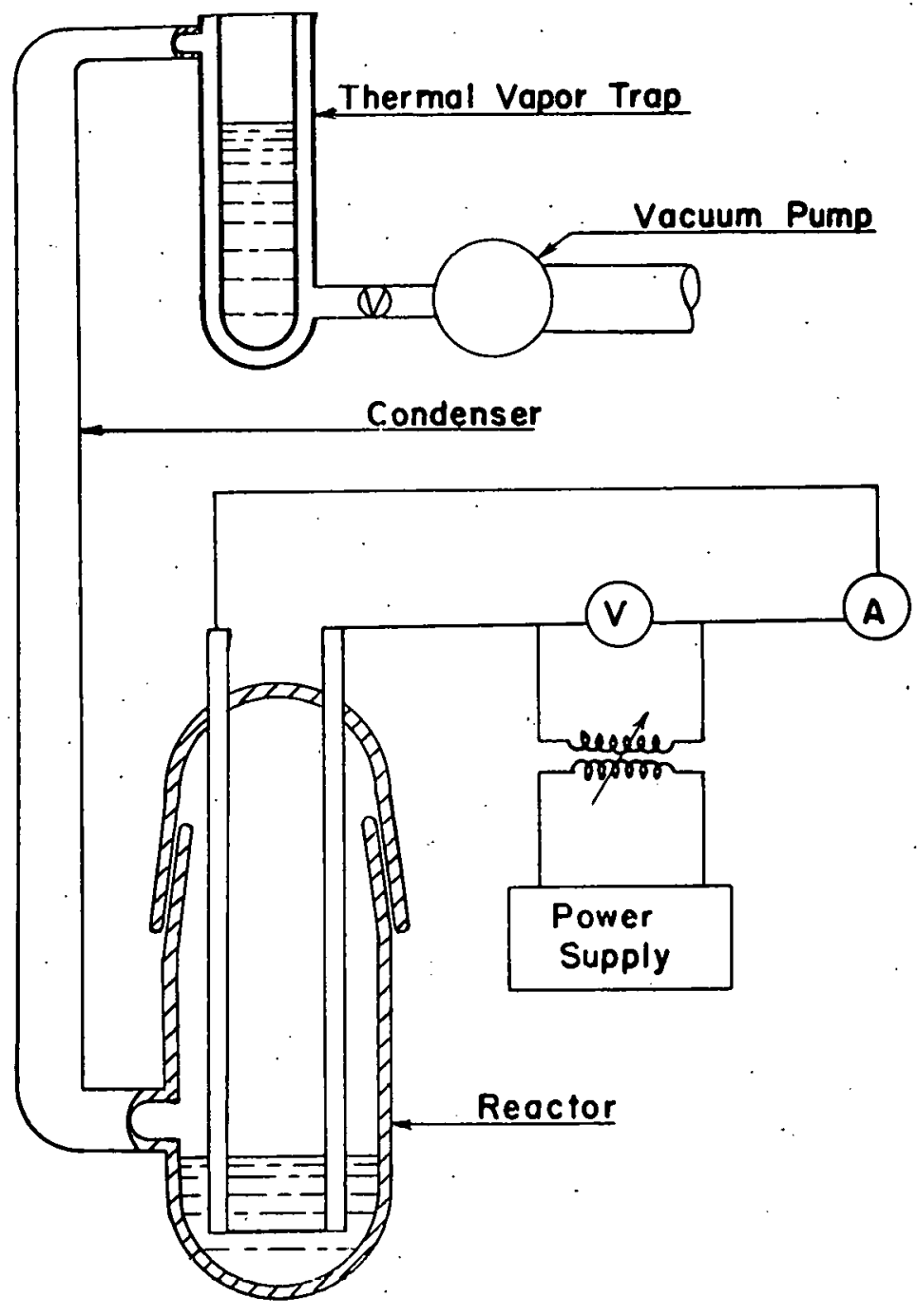

Fig. 2 
electrodes, was replaced. Freezing of the $\mathrm{TiI}_{4}$ was prevented by controlling the current to the nichrome wires wrapped around the reactor with a I KVA variable transformer. The mechanical vacuum pump was started and the system evacuated to about $2 \mathrm{mn} \mathrm{Hg} \mathrm{TiI} / 4$ vapor pressure, which corresponds to a liquid temperature of $160^{\circ} \mathrm{C}$. The current to the filament was turned on and the impressed voltage slowly increased with the variable transformer. A sudden drop in current at nearly constant impressed voltage indicated that film boiling had started; since, as the wire temperature rapidly increased, the resistance also increased, resulting in a current decrease. The variable transformer was then set so that the total resistance corresponded to a temperature in the range 1100 $1600^{\circ} \mathrm{C}$, which is the most favorable decomposition range for the Van Arkel-deBoer process: Usually the 0.010-inch-diameter filament fused after only about 30 seconds of operation. The apparatus was then disassembled and the characteristics of the deposit were noted. Results

The first metallic titanium prepared, as shown in the photograph (Figure 3), was on a 0.010 -inch-diameter tungsten wire 0.81 inches long between electrodes; the scale showing in the photograph is $1 \mathrm{~cm}$ in length. The deposition rate is calculated from the diameter of the uniform deposit; 0.019 inches, on the short, large-diameter middle section of the wire and from the time of deposition of 20 seconds; this corresponds to an average deposition rate for $T i$ of $9,000 \mathrm{mg} / \mathrm{cm}^{2} / \mathrm{hr}$ (Page 50, Appendix).

The initial current was 9.5 amps and the total voltage drop was 2.0 volts; this corresponds to a power input of $4 \mathrm{Kw} / \mathrm{hr} / \mathrm{lb} \mathrm{Ti}$. 


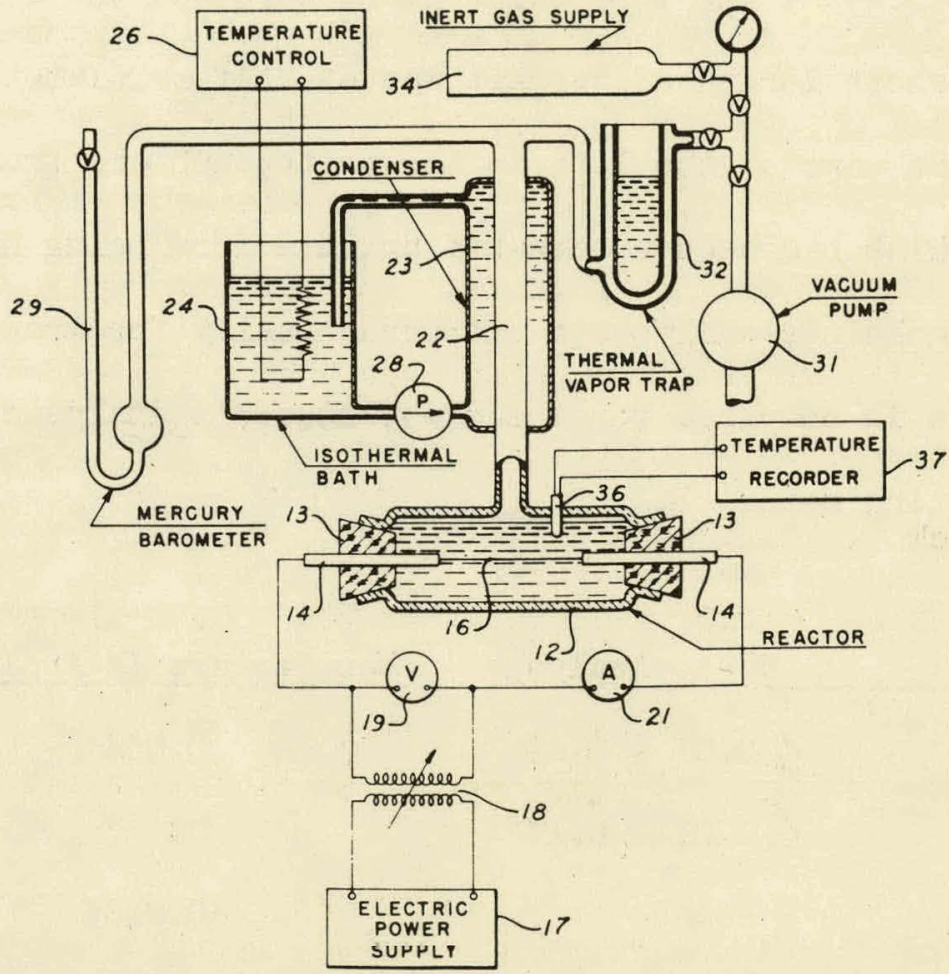

Fig. 3 
The current increased slightly as the run progressed, due to the increased cross section and resulting decreased resistance.

The deposit is not uniform over the length of the wire. Ti was formed only on the middle third of the wire length, where it formed in globules. The globule on the section on the right in the photograph formed as a result of the wire's fusing; the other globules probably were formed because the wire temperature exceeded the melting point of Ti; only a short length of deposit was of uniform diameter. The two breaks in the wire on the left in the photograph are from handling the tungsten, which had become somewhat brittle from being heated.

The sample was analyzed spectrographically for iron and tungsten. The analysis is compared for the manufacturer's analysis of the titanium sponge starting material.

Spec. Analysis Manufacturer's Analysis

\begin{tabular}{lcl}
\hline $\mathrm{Fe}$ & $\leq 0.01-0.1 \%$ & $0.05 \%$ \\
$\mathrm{~W}$ & $\leq 0.01-0.1 \%$ & $0 \%$ \\
$\mathrm{~N}_{2}$ & - & $0.018 \%$ \\
$\mathrm{Cl}_{2}$ & - & $0.12 \%$ \\
\hline
\end{tabular}


V. FILM BOILING ON LONG WIRES

\section{Apparatus}

The apparatus shown in Figure $4 a, 4 b$, Pages 18,19 , is for film boiling $\mathrm{TiI}_{4}$ on long wire filaments. The current supply and electrical instruments are the same as for the apparatus for short wires, except that the variable transformer is on the high-voltage side of the bank of three transformers. The current is conducted to the wire filament through two 0.080 -inch-diameter tungsten electrodes, which fit through teflon plugs on the ends of the reactor. The reactor may be assembled by pushing the plugs into the reactor and sliding the electrodes out through the plugs; a vacuum putty maintains a vacuum-tight seal at the teflon-electrode joint.

Nichrome wires, wrapped around the reactor to heat the $\mathrm{TiI}_{4}$ ? keep it liquefied and set the liquid temperature at any desired value at the beginning of a run. The liquid temperature is measured with a chromel-alumel thermocouple immersed in a wax-filled well and is recorded continuously with a "Speedomax" recorder. A similar arrangement with the well at the base of the condenser continuously measures and records the vapor temperature.

The reactor is attached to the condenser by a ball joint lubricated with high-vacuum silicone grease. The condenser temperature is maintained $\pm 2^{\circ} \mathrm{C}$ by circulating wax from a constant temperature bath, which uses a mercury contact switch and relay to actuate a heating coil in the wax; a small centrifugal pump circulates the wax through copper tubing to and from the condenser.

On the low-pressure side of the condenser is a mercury barometer for measuring the pressure of the noncondensible gases to $\pm 2 \mathrm{~mm} \mathrm{Hg}$. 
if

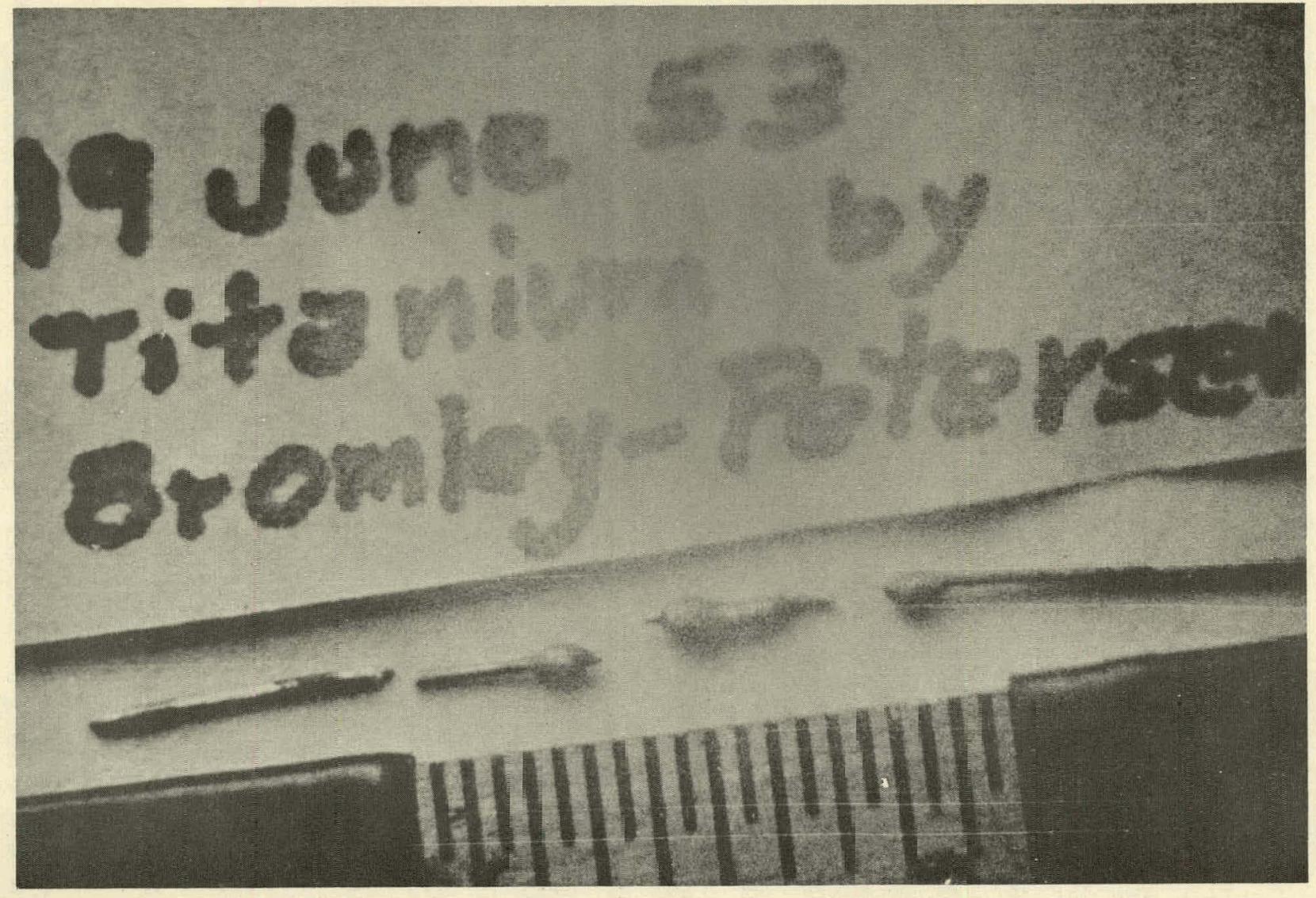

Fig. $4 a$ 


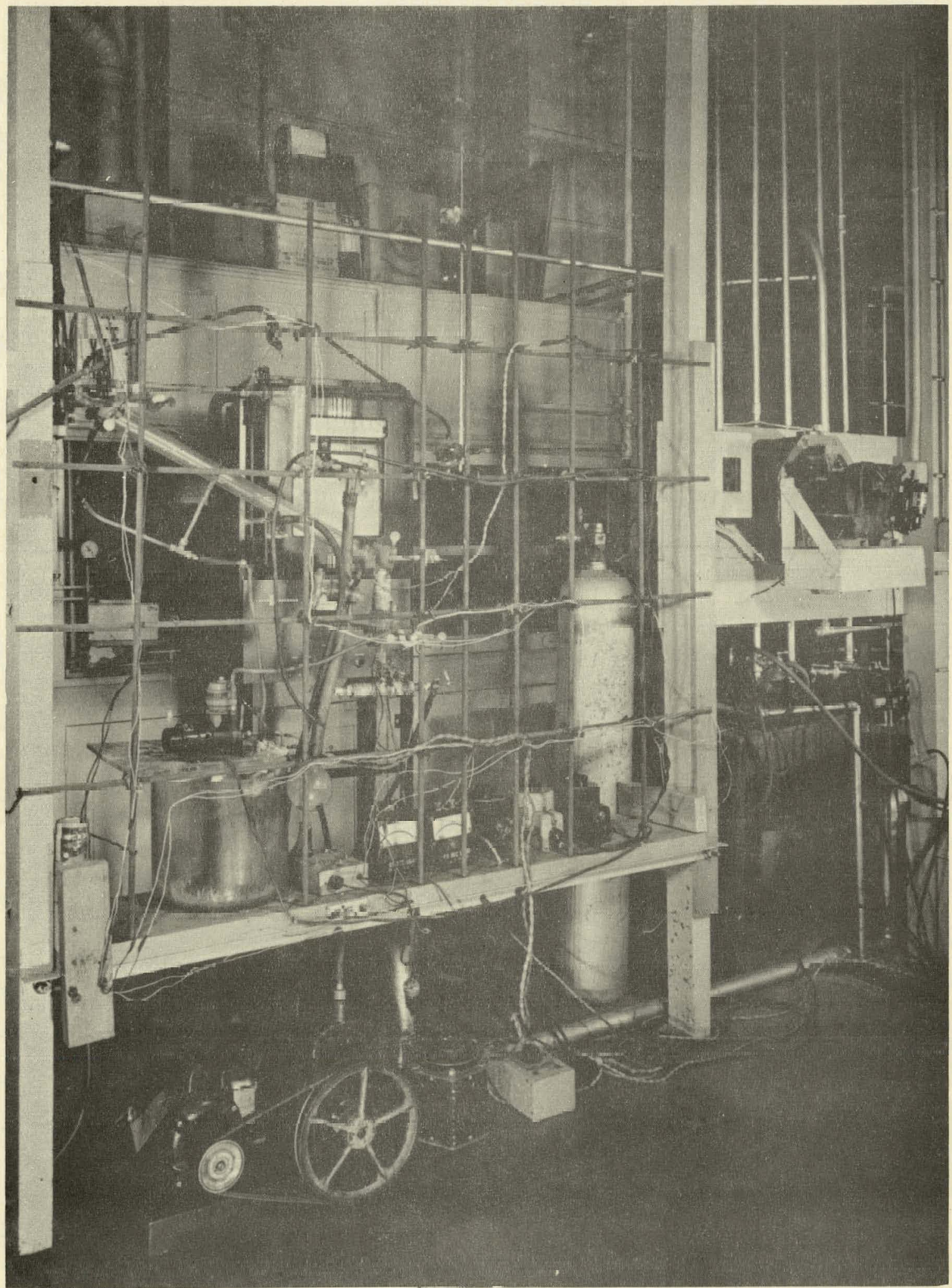

Fig. 4b 
16

An ice trap for corfosive vapors is inserted between the condenser and the mechanical vacuum pump. $\mathrm{A} \mathrm{CO}_{2}$ cylinder is attached near the ice trap for filling the system with inert gas when necessary. Procedure

The procedure for making a film-boiling run to deposit metallic Ti is described. The wire filament is hard soldered to the electrodes and this assembly is put into the reactor. $\mathrm{TiI}_{4}$ is melted and siphoned into the reactor, filling it about $7 / 8$ full. The reactor is attached to the condenser and the system is slowly evacuated to the desired pressure as indicated by the mercury barometer; this pressure is maintained by carefully adjusting the stopcock to the vacuum pump. The ice trap is filled, and wax is started cycling through the condenser. The current is turned on and the impressed voltage slowly increased in small increments. A sudden decrease in current at constant impressed voltage indicates film boiling has started. The current and total voltage are then set so that the wire resistance corresponds to a filament temperature in the range $1100-1600^{\circ} \mathrm{C}$; this was determined by a previous calibration using an optical pyrometer, with the filament in vacuo. A slightly increasing current at constant impressed voltage verifies that $\mathrm{TI}$ is depositing, due to decreased wire resistance. The run is continued until the wiro fuses; the apparatus is disassembled, and the characteristics of the deposit are noted.

Results

Film boiling was obtained on 0.010 -inch-diameter and 5.75 inches long tungsten wires in the apparatus shown in Figures $4 \mathrm{a}, 4 \mathrm{~b}$, Pages 18 and 19. Data obtained for three runs follow: 


\begin{tabular}{llccc} 
Total & \multicolumn{3}{c}{17} \\
Figure & $\begin{array}{l}\text { Initial } \\
\text { Voltage } \\
\text { (volts/inch) }\end{array}$ & $\begin{array}{c}\text { Initial } \\
\text { Current } \\
\text { (amps) }\end{array}$ & $\begin{array}{c}\text { Total } \\
\text { Initial } \\
\text { Resistance } \\
\text { (ohms/inch) }\end{array}$ & $\begin{array}{c}\text { Time } \\
\text { of run } \\
(\mathrm{sec})\end{array}$ \\
\hline $5 \mathrm{a}$ & 3.4 & 9 & 0.38 & - \\
$5 \mathrm{~b}$ & 2.7 & 8.5 & 0.32 & 15 \\
$5 \mathrm{c}$ & 2.2 & 9.3 & 0.24 & 33 \\
\hline
\end{tabular}

The Ti deposit, as show in Figure 5a, b and $c$, is in globules; attempts to obtain a smooth deposit with a 0.010 -inch-diameter wire were unsuccessful, and for this reason the deposition rate could not be calculated. The deposit appears only on short sections of the wire, and not over the entire length. One break in each wire is a result of the wire fusing, necessarily terminating the experiment; the other breaks are from handling.

An attempt was made to obtain film boiling on a $0.020^{\prime \prime}$ titanium wire (not shown). Film boiling was momentarily attained, before the wire fused. A very small globule of deposited Ti was obtained. However, experiments on Ti wire were discontinued due to the low Ti melting point, requiring very sensitive control of the impressed voltage to prevent the wire from fusing.

Deposition on 0.040 -inch $\mathrm{Ta}$ wires $3-4$ inches long was very successful. Data obtained from four runs follow: 
$-22-$

18

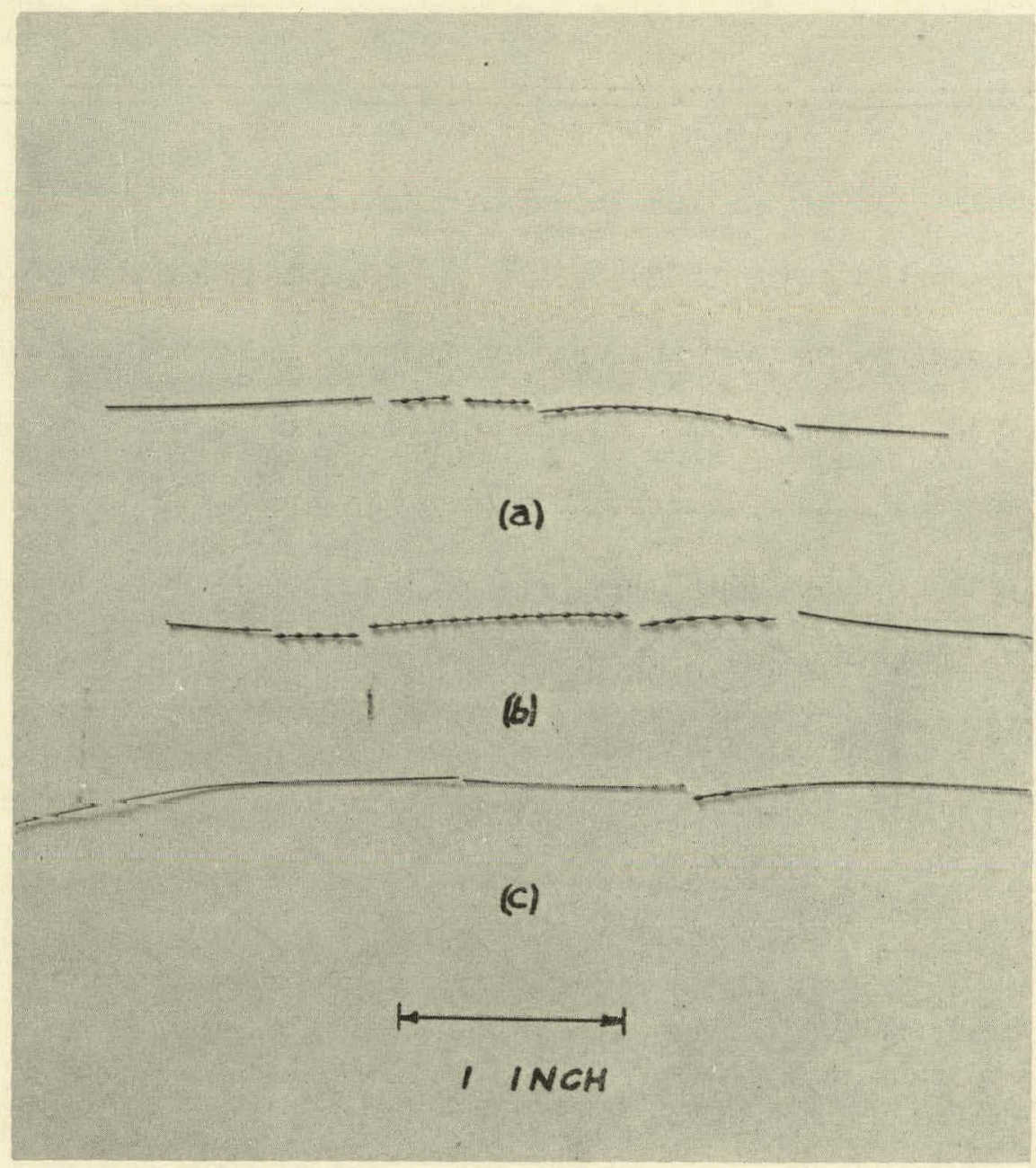

Fig. 5 


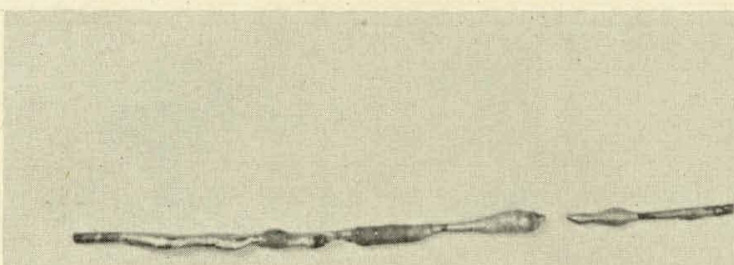

(a)
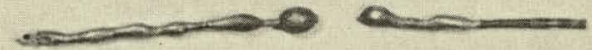

(b)

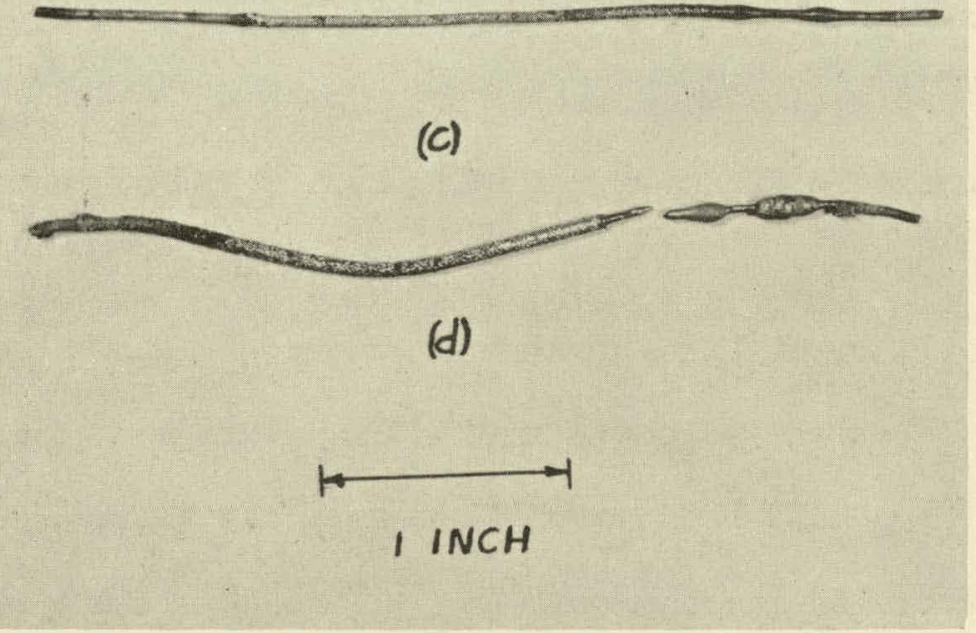

Fig. 6 


\begin{tabular}{|c|c|c|c|c|c|c|c|}
\hline Figure & $\begin{array}{c}\text { Total } \\
\text { Initial } \\
\text { Voltage } \\
\text { (volts/inch) }\end{array}$ & $\begin{array}{l}\text { Initial } \\
\text { Current } \\
\text { (amps) }\end{array}$ & $\begin{array}{l}\text { Initial } \\
\text { Power } \\
(\text { Kw-hr/Ib) }\end{array}$ & $\begin{array}{l}\frac{20}{\text { Initial }} \\
\text { Total } \\
\text { Resistance } \\
\text { (ohms/in) }\end{array}$ & $\begin{array}{l}\text { Time } \\
\text { of Run } \\
(\mathrm{sec})\end{array}$ & $\begin{array}{l}\text { Vapor } \\
\text { Temp. } \\
\left({ }^{\circ} \mathrm{C}\right)\end{array}$ & $\begin{array}{l}\text { Titanium } \\
\text { Deposition } \\
\text { Rate } \\
\left(\mathrm{mg} / \mathrm{cm}^{2}-\mathrm{hr}\right.\end{array}$ \\
\hline $\begin{array}{l}6 a \\
6 b \\
6 c \\
6 d\end{array}$ & $\begin{array}{l}1.33 \\
1.23 \\
- \\
1.27\end{array}$ & $\begin{array}{r}52 \\
49 \\
- \\
54\end{array}$ & $\frac{2}{-}$ & $\begin{array}{l}.026 \\
.025 \\
.023\end{array}$ & $\begin{array}{r}60 \\
- \\
300\end{array}$ & $\begin{array}{c}- \\
- \\
178 \stackrel{-}{-}-180\end{array}$ & $\begin{array}{c}12,000 \\
- \\
1,600\end{array}$ \\
\hline
\end{tabular}

Part of the denosit on the wire in Figure $6 \mathrm{a}$ was Iumpy, indicating tho temparature of the $f^{\circ} j$ lament, reached the melling nuint of Ti $\left(1740^{\circ} \mathrm{C}\right)$; this made the deposit sag on part of the wire. However, a short length of uniform deposit was used to calculate the deposition rate of Ti as $12,000 \mathrm{mg} / \mathrm{cm}^{2}-\mathrm{hr}$ (Page 50, Appendix). The cross section of this deposit was not perfectly circular, being 0.082 inches in vertical diameter and 0.074 inches in horizontal diameter; this deposit was porous and rough, indicating that it probably had not been melted.

The deposit in Figure $6 \mathrm{~b}$ is entirely Iumpy, and no deposition rate was calculated.

The small, crystalline deposit in Figure $6 \mathrm{c}$ was obtained at a temperature below the melting point of Ti. This wire did not fuse, because the hard solder connection became loose after a short time, necessarily terminating the run.

The uniform deposit in Figure 6d was obtained by earefuI control of the Impressed voltage to keep the wire temperature lower than tho melting point of Ti. The deposit did not sag and formed almost concentrically around the wire to a diameter of 0.064 inches, at an average deposition rate of $1,600 \mathrm{mg} / \mathrm{cm}^{2} \mathrm{mr}$. Near the end of the run, the impressed voltage was raised considerably, resulting in local overheating and fusing near one end of the wire, terminating the experiment. 


$$
21
$$

Spectrographic analysis of some of the Ti. which had melted

(Figure 6a) showed a gain of $15 \% \mathrm{Ta}$ and an $\mathrm{Fe}$ analysis of about $0.05 \%$ (compared to $0.05 \% \mathrm{Fe}$ in the $\mathrm{Ti}$ starting material). 
VI. DISCUSSION OF RESULTS

Measurement of Variables.

The quantitative results in this thesis have certain limitations imposed by the difficulty of measuring some physical variables; therea; fore, the quantitative results given may be used only as orders of magnitudes. The latter part of this thesis is devoted to the design of apparatus for more accurate measurement of the variables.

The most important variable with respect to deposition rate is the filament temperature (Figure 14 , Page 53), which is very difficult to measure when wire filaments are used. A thermocouple attached to the wire would have to be small diameter in order not to conduct too much heat from the filament and not to change the temperature appreciably; delicate wires of platinum and platinum-10\% rhodium (necessary to withstand corrosion and high temperatures) would not easily withstand violent film boiling and would be difficult to handle. It is possible to use the variation in electrical resistance with temperature, in order to determine the fillament temperature. The wire must be calibrated in vacuo with an optical pyrometer in order to obtain temperature vso resistance. This method was actually used in order to determine the approximate current and voltage to set the filament temperam ture in the range $1100-1600^{\circ} \mathrm{C}$. However, the method is inaccurate due to end effects from-heat conduction into the electrodes, changing the electrical resistance near the ends. $\mathrm{Also}$, the method is restricted to the beginning of a run, since titanium deposition decreases the electrical resistance. Exact temperature measurements may be made only by film boiling TiI $_{4}$ on a tube, and inserting a thermocouple 


\section{3}

within the tube; suitable equipment for using a tube is and in the latter part of this thesis.

The pressure is not easily measured directly, due to the corrosive, condensible gases. However, a good indication of the total pressure and $\mathrm{TiI}_{4}$ vapor pressure may be obtained by measuring the noncondensible gas pressure on the low-pressure side of the condenser and by measuring the $\mathrm{TiI}_{4}$ vapor temperature as it boils off the liquid in order to obtain the vapor pressure above the liquid; the sum of these two pressures plus the liquid head give the total pressure at the filament; the sum of the above vapor pressure and the liquid head give the $\mathrm{TiI}_{4}$ vapor pressure at the filament.

Current and voltage must be measured in order to obtain power consumption; current is easily directly measured; voltage is not easily measured exactly with wire filaments, due to end effects from heat conduction into the electrodes, changing the voltage drop. In the data given, the voltage is not corrected for these end effects. However, this error would not be more than 10-20\%, which is within the accuracy of other data used. Accurate voltage measurements may be made by inserting a voltage probe into a tube on which $\mathrm{TiI}_{4}$ is film boiling.

Time of deposition must be measured in order to calculate deposition rate. There is a small time lag at the beginning of a run in which the temperature is rising through the deposition temperature range to the desired setting; the same lag is observed at the end of a run when the current is turned off. This uncertainty of the 'length of time of a run may be minimized by Ionger runs than used for this thesis, so that the possible error is within the limit of other experimental errors. 


\section{Deposition Rate}

\section{4}

The approximate"deposition rates calculated for thee separate runs were 1,$600 ; 9,000$; and $12,000 \mathrm{mg} / \mathrm{cm}^{2}-\mathrm{hr}$. These rates may be compared with the approximate range of rates obtained by Runnalls and Pidgeon ${ }^{15}$ of $10-100 \mathrm{mg} / \mathrm{cm}^{2}-\mathrm{hr}$. for the Van Arkel-deBoer process for making, Ti。 It may be concluded that the film boiling process rate is much higher than tho Von Mrhol-deBoer prooees. Power Input

The approximate power inputs necessary for the above three runs were 19; 4 ; and $2 \mathrm{Kw} w \mathrm{hr} / \mathrm{Ib}$ Ti。. The power input required for a present commercial installation using the Van Arkel-deBoer process is 40-60 $\mathrm{KW}-\mathrm{hr} / \mathrm{lb}$ Ti. ${ }^{8}$ A pilot-plant-scale installation uses $80-90 \mathrm{KW}-\mathrm{hr} / \mathrm{Ib}$ $\mathrm{Ti}^{8}$ It may be concluded that there is an appreciable saving in power by film boiling, even with the least efficient laboratory-scale film boiling run.

Purity of Product

The purity of the Ti made has not been conclusively determined。 The manufacturer's analysis of the Ti sponge for $\mathrm{Fe}$ of $0.05 \%$ is the same order of magnitude as the two analyses of about $0.05 \%$ and $\leq$ $0.01-0.1 \%$. The wire materials of $\mathrm{Ta}$ and $\mathrm{W}$ dissolved somewhat in the Ti deposits which had melted。 Character of Deposit

The character of the deposit varied, being smooth or rough and lumpy or uniform in different runs. The deposit in Figure 3, Page 15. has a uniform section of deposit on the large-diameter short piece; the other half of this piece has a globule. This is probably due to part of the wire's being at a temperature greater than the melting 


\section{5}

point of $\mathrm{Ti}\left(1740^{\circ} \mathrm{C}\right)$; the $\mathrm{Ti}$ would tend to form into a globule from surface tension when it is liquid. The deposits in Figures $5 a, b$ and $c$, are all in globules, indicating the temperature was above the melting point of Ti. Part of the deposit in Figures $6 a$ and $b$ has sagged on the wire due to melting, while part of the deposit is somewhat uniform and has a rough surface, indicating it probably had not been melted. The current was carefully controlled, lower than other runs, for the deposits in Figures $6 c$ and $d$. These deposits are uniform and rough, so had not been meited.

Some deposits, as in Figures $5 \mathrm{a}, \mathrm{b}$ and $\mathrm{c}$, formed on only a small part of the original 5.75 inch length. This is due to the difficulty of obtaining film boiling over the entire length of wire without fusing part of the wire. The larger diameter Ta wires, 0.040 in diameter, in Figures $6 a, b, c$ and $d$, have a deposit over most of the length, except at the cool ends. A few experiments with 0.300 inch diameter tubes showed that it was easy to obtain film boiling uniformly over the length of the tube. Thus, a large diameter, 0.040 inches or larger, will eastly give uniform film boiling over the length of heating surface.

On almost all of the runs, except in Flgure $6 c$, the wires fused, terminating the experiment. It is suggested that this occurred due to local overheating on a wire, melting the Ti deposit. The liquid Ti then dropped off, leaving the original bare wire to carry the current; it could not carry the higher current resulting from Ti deposition and fused. 
$-30=$

26

VII. THEORY OF TITANIUM DEPOSITION

Effect of Diffusion Path Length

A mechanism for the deposition of $T i$ on a hot surface, consistent with observations on both the Van Arkel process and film boiling process, will be proposed.

Runnals and Pidgeon ${ }^{15}$ observed that the length of diffusion path from filament to crude $\mathrm{Ti}$ had a pronounced effect upon the deposition rate in the Van Arkel process. Since excess liquid TiI 4 was present and the vapor was perceptibly saturated with it, they concluded that adequate $\mathrm{TiI}_{4}$ was present to continue the reaction

$$
\mathrm{TiI}_{4}(\mathrm{~g}) \longrightarrow \mathrm{Ti}(\mathrm{s})+4 \mathrm{I}(\mathrm{g}) \text { 。 }
$$

They suggested that the equilibrium iodine pressure is low in this reaction and quickly rises to the saturation value. Thermodynamic calculations (Table 3, Page 38) from the data in Quill, 14 indicated that this could be correct considering the uncertainty of the data. The rate of diffusion of iodine to the crude $\mathrm{Ti}_{\text {, whe }}$ wh is removed from the system as it forms $\mathrm{TiI}_{4}$, is dependent upon the diffusion path length; as a result of this the rate of deposition would be dependent upon the path length, since rate of deposition is dependent

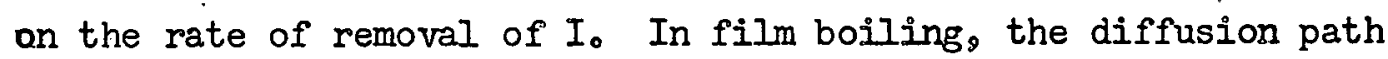
length for iodine is very short; it must diffuse merely through the thickness of the vapor film to the liquid $\mathrm{TiI}_{4_{4}}$, where the iodine is considered to be removed from the region of the fillament. It would be expected from the above that the rate of reaction would be very large in film boiling, and this has been observed. Figure.7, Curve Ig Page 31, suggests a method of correlation for deposition rate 


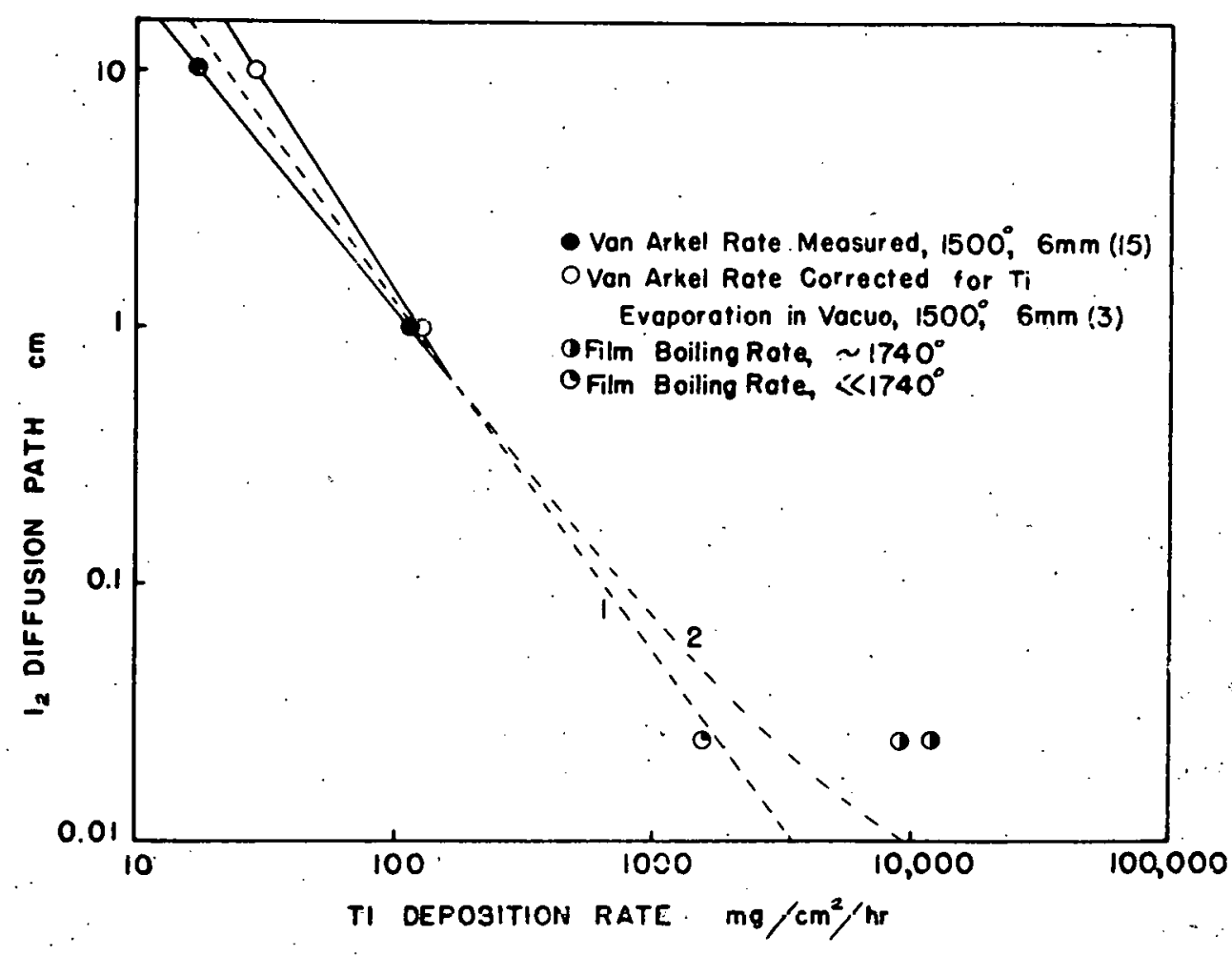

F1g. 7 


\section{8}

vs. length of diffusion path, using the data of Runnalls and Pidgeon for the Van Arkel process and very approximate film boiling data. The rate of deposition for the Van Arkel process must be corrected for the evaporation rate of Ti at $6 \mathrm{~mm} \mathrm{Hg}$ and $1500^{\circ} \mathrm{C}$. This rate is not accurately known, but the corrected deposition rate will be somewhere between the uncorrected deposition rate and the deposition rate corrected tor the maximum possible Ili evaporation rate (in vacuo). For film boiling, the evaporation rate is negligible in comparison to the deposition rate. The film boiling data are only approximate, because the temperature of deposition, a very important variable, is not known. The temperature for two points reached at least $1740^{\circ} \mathrm{C}$ (melting point of $\mathrm{Ti})_{2}$ since the deposits appeared to have melted. The deposit for the third mun was not melted and the temperature must have been less than $1740^{\circ} \mathrm{C}$, and was probably even less than $1500^{\circ} \mathrm{C}$, since the current was carefuliy controlled at a low value. The film thickness of $0.025 \mathrm{~cm}$ may be considerably in error, since it was calculated by a correlation ${ }^{5}$ (Page 50, Appendix) which holds best only for wires $>0.040$ in diameter and which used many estimated physical properties of $\mathrm{TiI}_{4}$ vapor. The pressure for the film boiling data is not accurately known: however, the effect of TiI ${ }_{4}$ vapor pressure up to $25 \mathrm{~mm} \mathrm{Hg}$ is not large and is within the accuracy of the data. Thus, the plot in Figure 7 may be used only to show. the trend of deposition rate vs. diffusion path length.

\section{Effect of Temperature}

It has been shown above that the rate of deposition depends upon the rate of removal of iodine from the region of the filament. Removing iodine would tend to displace the approximate equilibrium 
represented by

$$
\mathrm{TiI}_{4}(\mathrm{~g}) \rightleftarrows \mathrm{Ti}(\mathrm{s})+4 \mathrm{I}(\mathrm{g}) \text {. }
$$

The equilibrium constant for this reaction may be written as

$$
K=\frac{(\mathrm{Ti})(\mathrm{I})^{4}}{\left(\mathrm{TiI}_{4}\right)}=\frac{(\mathrm{I})^{4}}{\left(\mathrm{TiI}_{4}\right)}
$$

using ( $\mathrm{T} i$ ) solid $=I$ in the standard state. Since $\mathrm{TiI}_{4}$ pressure is held constant, ( $\mathrm{TiI}_{4}$ ) at the filament is assumed to be approximately constant. with temperature。 Then

$$
K \propto(I)^{4}
$$

or

$$
\log K \propto \log (I)^{4} \propto 4 \log (I) \propto \log (I) 。
$$

The equivalent deposition rate $r$ is equal to the equivalent diffusion rate $N_{A}$ of iodine。 $N_{A}$ is given by

$$
N_{A}=k\left(\left(I_{2}\right)-\left(I_{2}\right)_{0}\right)
$$

where $\left(I_{2}\right)$ is the iodine concentration a short distance from the hot filament where most of the atomic iodine has changed back to molecular iodine, and $\left(I_{2}\right)_{0} \cong 0$ is the iodine concentration near the crude Ti。 The temperature over the diffusion path of $10 \mathrm{~cm}$ length is not constant; but the diffusion coefficient, which depends upon the temperature, is assumed constant for this derivation, since there is a relatively long diffusion path and most of the path is at the temperature of the bulk $\mathrm{TiI}_{4}$ vapor. The effect of shortening the diffusion path, as in film boiling, will be discussed later。 $\mathrm{N}_{\mathrm{A}}$ is then approximately proportional to $\left(I_{2}\right)$,

$$
r=N_{A} \propto\left(I_{2}\right) .
$$

As the atomic I moves away from the filament and cools, it changes to 
molecular iodine; and the amount of $I_{2}$ being formed is proportional to the $I$ concentration near the filament $\left.\left(I_{2}\right) \propto I\right)$ and

$$
r \propto(I)
$$

from Equation (6).

Substitute Equation (8) into Equation (4) and

$$
\log \mathrm{K} \propto \log \mathrm{P}
$$

The log of an equilibrium constant for a reaction is known to be proportional to $1 / 19$ or

$$
\log \mathrm{K} \propto \log \propto \mathrm{s} / \mathrm{T}
$$

So a plot of $\log \mathfrak{2}^{\prime}$ vs。 $1 / T$ should be a straight line if the previous assumptions are correct. The data of Runnalls and Pidgeon for a diffusion path length of $10 \mathrm{~cm}$ are reproduced in Figure 14, Page 53. These data must be corrected for the evaporation rate of Ti. This will give a deposition rate somewhat between the uncorrected deposition rate and the deposition rate corrected for evaporation of $T I$ in vacuo. As shown by Figure 8 , Page 35 , a straight line is approximated by $\log \mathbf{r}$ vs. I/T. Thus, the effect of temperature is to shift the equilibrium and allow a higher (I) concentration at the filament. If the diffusion path length were shortened, as in film boiling, $\therefore$

6. the assumption of constant diffusion coefficient due to a negligible tempcrature gradient from a long diffueion path in the Van Arkel process would not hold. There would be a steep gradient over the short distance; the iodine would diffuse at a higher average temperature, resulting in a higher deposition rate than would be predicted by extrapolation of Van Arkel data; this would agree better with the data in Figure 7 . Page 31 , as shown by Curve 2 . 


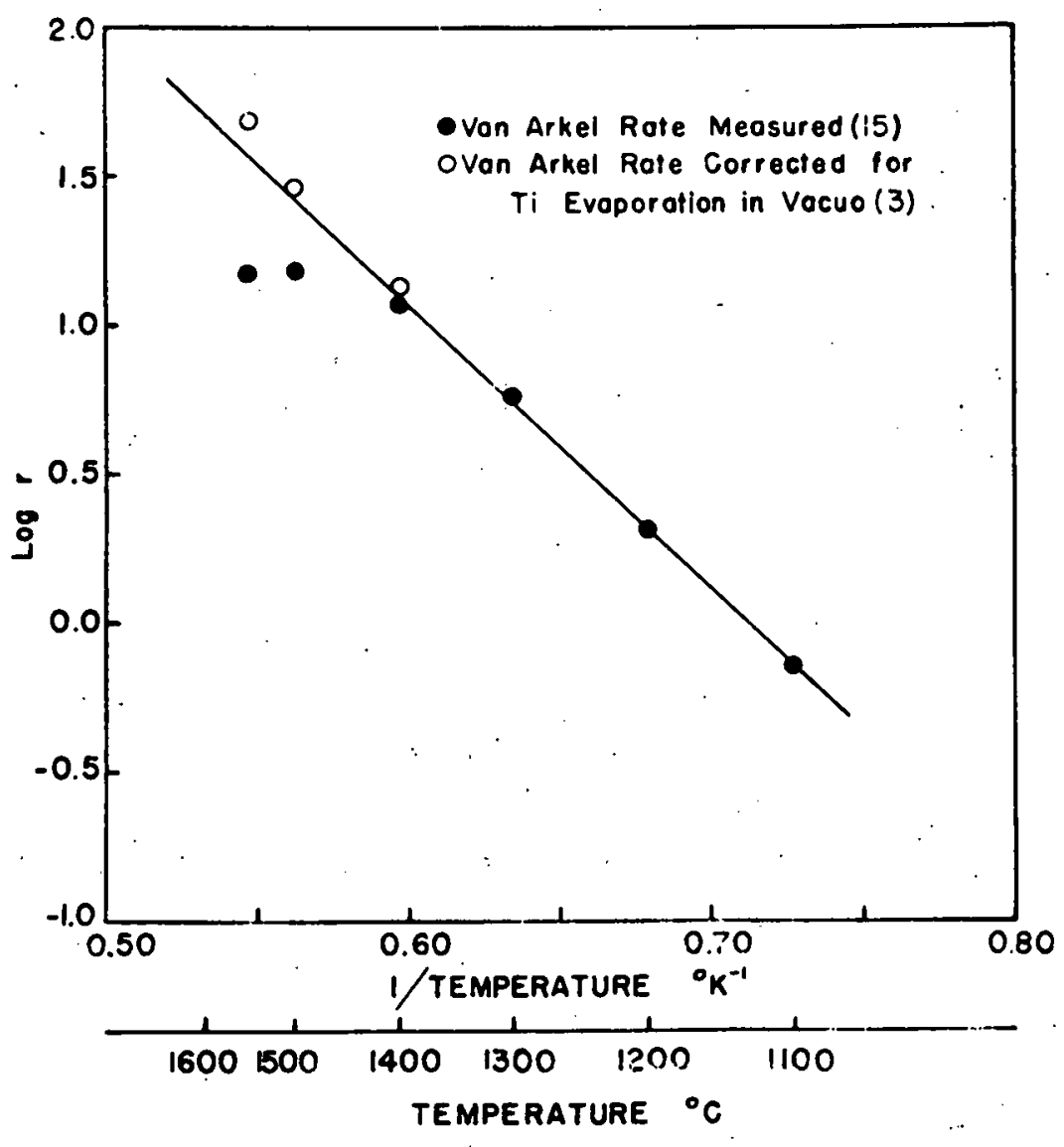

Fig. 8 
The deposition rate apparently decreases past $1500^{\circ} \mathrm{C}$ (Figure $14 \mathrm{~g}$ Page53) for the Van Arkel process. This is explained by the fact that evaporation rate of $\mathrm{T}^{\mathrm{i}}$ becomes appreciable above $1350^{\circ} \mathrm{C}(2)$; at $1500^{\circ} \mathrm{C}$, the deposition rate observed was $14.7 \mathrm{mg} / \mathrm{cm}^{2} \mathrm{chr} \mathrm{h}^{15}$ while the evaporation rate in vacuo was $12.6 \mathrm{mg} / \mathrm{cm}^{2} \mathrm{chhr}^{3}$; at $1550^{\circ} \mathrm{C}$, the deposition rate was $14.3 \mathrm{mg} / \mathrm{cm}^{2}-\mathrm{hr}$, while the evaporation rate was $32.4 \mathrm{mg} / \mathrm{cm}^{2} \mathrm{wh}$ 。 For film boiling of $\mathrm{TII}_{4}$, the evaporation rate of $\mathrm{T} I$ is negligible compared to the rate of deposition up to the melting point of Ti。

\section{Effect of Pressure}

The data of Runnalls and Pidgeon, ${ }^{15}$ reproduced in Figure 15, Page 5h, show that the rate of deposition increases up to about $15 \mathrm{~mm} \mathrm{TiI}_{4}$ pressure at $1500^{\circ} \mathrm{C}$ and then decreases up to about $37 \mathrm{~mm}$; at $50 \mathrm{~mm}$ $\mathrm{TiI}_{4}$ pressure previously deposited $\mathrm{Ti}$. was removed, ${ }^{15}$ suggesting a negative deposition rate at pressures above $37 \mathrm{~mm}\left(1500^{\circ} \mathrm{C}\right)$; above $25 \mathrm{~mm} \mathrm{TiI} 3$ was formed on the cool electrodes.

It is suggested that the increase in deposition rate up to $15 \mathrm{~mm}$ is a result of shifting to the right the equilibrium

$$
\mathrm{TiI}_{4}(\mathrm{~g}) \Longleftrightarrow \mathrm{TI}_{(\mathrm{s})}+4 \mathrm{I}_{(\mathrm{g})} \text {. }^{2}
$$

allowing a slightly higher (I) concentration according to

$$
K=(I)^{4} /\left(\mathrm{TiI}_{4}\right) \text {. }
$$

and hence an increased deposition rate, since it is dependent upon (I) concentration.

Above $15 \mathrm{~mm}$, it is evident that the rate of a reaction involving the removal of $\mathrm{Ti}$ and formation of $\mathrm{TiI}_{3}$ becomes of the same order of magnitude as $\mathrm{Ti}$ deposition. In order to determine what this reaction is, standard free energies will be used to estimate the partial pressure of the various components in the vicinity of the filament in equilibrium 
with Ti $(s)$; the assumption of equilibrium may not hold, but the results may at least indicate the tendency of reactions. The free energy data from Quill ${ }^{14}$ hovs an estimated uncertainty of $\pm 10 \mathrm{kcal}, / \mathrm{mole}$, which corresponds to an uncertainty by a factor of 30 in the calculated partial pressures at $1500^{\circ} \mathrm{K}$. The data given in Table 2, Page 38; the calculated partial pressures are given in Table 3, Page 38. .

The accuracy of the thermodynamic data may be checked by imposing the condition that at zero net Ti deposition, the ratio of atomic concentration of $\mathrm{Ti}$ in all gaseous species to atomic I concentration in all gaseous species is $1 / 40$ as in the starting material TiI $4:$

$$
\frac{\Sigma\left(\mathrm{TiI}_{4}\right)+\left(\mathrm{TiI}_{3}\right)+\left(\mathrm{TiI}_{2}\right)}{\Sigma 4\left(\mathrm{TiI}_{4}\right)+3\left(\mathrm{TiI_{3 }}\right)+2\left(\mathrm{TiI}_{2}\right)+(\mathrm{I})}=1 / 4 .
$$

This may be seen to hold true by noting that $\mathrm{TiI}_{4}$ may decompose to any of the above four gases, without Ti deposition, and the ratio of concentrations remains constant at $1 / 4$; however, remove $T i$ from the: gaseous system by depositition and the ratio becomes less than $1 / 4 ;$ by similar reasoning, the ratio becomes greater than $1 / 4$ when $T$ is is: removed from the fillament and added to the gaseous system. For a total pressure of $50 \mathrm{~mm}$ at the filament (Table 3, Page 38), the above ratio is 0.49 , indicating that $T i$ should be removed from the filament; this has been observed. 15 For a total pressure of $6 \mathrm{~mm}$, the ratio is 0.45, also indicating Ti removal; however, deposition has been observed at this pressure. ${ }^{15}$ Thus, the free energies are somewhat in error. By decreasing the $\mathrm{TiI}_{2}$ concentration by a factor of 30 (the possible error in the free energies stated by Quill $1^{14}$ ), the ratio becomes 0.149 indicating $\mathrm{T} i$ deposition as it should. It may be concluded that the 
$-38$

\section{4}

Table 2

Standerd Free Energy ${ }^{1 / 4}$

\begin{tabular}{|c|c|c|}
\hline Reaotion & $\begin{array}{c}\Delta \mathrm{F}_{1500^{\circ} \mathrm{K}} \\
(\mathrm{kcal} / \mathrm{mole})\end{array}$ & $\begin{array}{c}\Delta \mathrm{F}^{\circ} \\
500^{\circ} \mathrm{K} \\
(\mathrm{kcal} / \mathrm{mole})\end{array}$ \\
\hline $\mathrm{TiI}_{4(\mathrm{~g})} \longrightarrow \mathrm{TI}(\mathrm{s})+4 \mathrm{I}_{(\mathrm{g})}$ & $+38 \pm 10$ & $\because+146 \pm 10$ \\
\hline$\longrightarrow \mathrm{Ti}(\mathrm{s})+3 \mathrm{I}_{(\mathrm{g})}$ & $+20 \pm 10$ & $+111 \pm 10$ \\
\hline $\mathrm{TiI}_{2(\mathrm{~g})} \longrightarrow \mathrm{Ti}_{(\mathrm{s})}+2 \mathrm{I}(\mathrm{g})$ & $+24 \pm 10$ & $+82 \pm 10$ \\
\hline
\end{tabular}

Table 3

Partial Pressures of Components in Equilibrium with Ti at $1500^{\circ} \mathrm{K}$

\begin{tabular}{|c|c|c|c|c|c|}
\hline $\begin{array}{l}\text { Total Pressure } \\
\qquad(\mathrm{mm})\end{array}$ & $\begin{array}{l}\mathrm{TiI}_{4} \\
(\mathrm{~mm})\end{array}$ & $!$ & $\begin{array}{l}\mathrm{TiI}_{3} \\
(\mathrm{~mm})\end{array}$ & $\begin{array}{l}\mathrm{TiI}_{2} \\
(\mathrm{~mm})\end{array}$ & $\begin{array}{c}I \\
(\mathrm{~mm})\end{array}$ \\
\hline 50 & 0.1 & & 0.05 & 47 & 3 \\
\hline 6. & 0,001 & & 0.002 & 5 & 1 \\
\hline
\end{tabular}




\section{5}

TiI 2 partial pressures calculated are somewhat high and that the stability of $\mathrm{TiI}_{2}$ is not so great as indicated, though is certainly still large。

To explain the removal of Ti at high $\mathrm{TiI}_{4}$ pressure, the following mechanism is suggested, due to the large tendency of $\mathrm{TiI}_{2}$ to form in the region of the filament:

$$
\mathrm{TiI}_{4}(\mathrm{~g})+\mathrm{Ti}(\mathrm{s}) \longrightarrow 2 \mathrm{TiI}_{2(\mathrm{~g})}
$$

An increase of $\mathrm{TiI}_{4}$ pressure would favor the formation of $\mathrm{TiI}_{2}{ }^{\circ}$ Another mechanism could be proposed,

$$
3 \mathrm{TiI}_{4(\mathrm{~g})}+\mathrm{Ti} \longrightarrow 4 \mathrm{TiI} I_{3(\mathrm{~g})}:
$$

however, this reaction appears unlikely because there is little tendency for $\mathrm{TiI}_{3}$ to form in the vicinity of the filament and it is required that three $\mathrm{TiI}_{4}$ molecules collide with a $\mathrm{Ti}$ atom for the reaction to take place。

The formation of $\mathrm{TiI}_{3}$ on the cool electrodes may be explained by the greater stability of $\mathrm{TiI}_{3}$ at lower temperatures as in the bulk of $\mathrm{TiI}_{4}$ vapor。 At this temperature, about $500^{\circ} \mathrm{K}_{9}$ and a $\mathrm{TiI}_{4}$ pressure of $25 \mathrm{~mm}_{3}$ the $\mathrm{TiI}_{3}$ pressure calculated from Iree energy data is $0.2 \mathrm{~mm}$ for an assumed $T i I_{2}$ pressure of $I \mathrm{~mm}$; these constituents are not assumed to be in equilibrium with Ti at this low temperature. Thus, the formation of $\mathrm{TiI}_{3}$ from

$$
\mathrm{TiI}_{4(\mathrm{~g})}+\operatorname{TiI}_{2(\mathrm{~g})} \Longleftrightarrow 2 \mathrm{TiI}_{3}(\mathrm{~g})
$$

appears possible; considering that the stability of $\mathrm{TiI}_{2}$ is probably over-estimated, the reaction could be very favorable. The reaction has been shown to be reversible by Fast, ${ }^{6}$ and removal of TiI 3 by condensation would also tend to favor the reaction.

The effect of pressure in film boiling is similar to the Van Arkel process. A good deposit is obtained at lower $\mathrm{TiI}_{4}$ pressures of $6-10 \mathrm{~mm}$; 
these include $\mathrm{TiI}_{4}$ liquid head. No deposit was obtained above $20 \mathrm{~mm}$, although it may be possible. When the pressure was too high, no Ti deposit was found on the wire, but a dark-colored substance was observed to deposit. An $\mathrm{x}$-ray diffraction analysis of this substance showed only a small amount of $\mathrm{TiI}_{4}$ and no TiO, $\mathrm{TiN}$, or $\mathrm{TiO}_{2}$; it is thought that the substance is either $\mathrm{TiI}_{2}$ or $\mathrm{TiI}_{3}$, but no diffraction patterns for these substances were available for comparison with the unknown pattern. 
VIII. DESIGN OF APPARATUS FOR FIIM BOILING ON TUBES

\title{
Materials of Construction
}

The materials of construction must be resistant to $\mathrm{TiI}_{4}$ liquid and vapor up to $250^{\circ} \mathrm{C}$, small concentrations of $I_{2}$ vapor up to $250^{\circ} \mathrm{C}$, and HI gas which is formed as a result of $\mathrm{TiI}_{4}$ decomposition from hydrolysis with the unavoidable traces of water vapor that will get into the apparatuso. The materials which have been found to satisfy experimentally all of the requirements are as follows:

\author{
Tungsten \\ Tantalum \\ Platinum \\ Molybdenum \\ Hastelloy C \\ Glass
}

The first four metals are rather expensive and the size of the apparatus would restrict their use. Glass is entirely resistant and may be used in some parts of the apparatus; however, there is no advantage of using glass to see inside, because $\mathrm{TiI}_{4}$ liquid is opaque; glass has the disadvantages of breaking easily and of being difficult to seal vacuum-tight to metal with such a highly corrosive media. Hastelloy C (manufactured by the Haynes Stellite $C_{0}$ ) is completely resistant, and is available in sheet, rod, tubing, valves and pipe fittings, welding rod, and completely fabricated units; however, it is very hard (160-215 Brinell) and difficult to machine, though not impossible. On the basis of the previous discussion, Hastelloy $\mathrm{C}$ is the metal of choice. 
Consideration may be given to certain other metals which are not entirely corrosion-resistant。 Hastelloy B has been used previously in the design of a unit for Ti deposition by the Van Arkel-deBoer process; however, it is slightly harder than Hastelloy c. (190-235 Brinell)。 Stainless steel (302) is fairly resistant to hot TiI $4^{\text {}}$ but rusts in the presence of HI vapors arul dif; it is possible that more expensive stainless steels, 316 for example, would be more resistant. Inconel and monel are corroded even by hot $\mathrm{TiI}_{4}$, so should not be used. The use of aluminum should be investigated, as it would be a good electrode material due to high electrical conductivity.

Gasket materials are very limited. Teflon is resistant to $I_{2}$ and $\mathrm{HI}$ and is fairly resistant to hot $\mathrm{TiI}_{4}$ liquid; teflon is highly recommended. Blue asbestos has not been tested experimentally, but data in Perry ${ }^{13}$ are favorable. Rubber and cork are not resistant to the materials used. $\mathrm{TiI}_{4}$ Condenser Design

The condenser design is show in Figure 11, Page 4\% A coolant of liquid wax has previously been used for a small film boiling apparatus; however, wax has the disadvantages of being a solid at room temperature, of fuming in the open air, and of having a low heat-transfer coefficient. A better coolant would be water under a pressure of about 60 psia in order to give a temperature of $145^{\circ} \mathrm{C}$ ( $\mathrm{m}_{\circ} \mathrm{p}$ of of $\mathrm{TiI}_{4}$ is $144^{\circ} \mathrm{C}$ ). A steam line with a pressure regulator would maintain the desired pressure, and a water cooling coil could condense the water vaporized from condensing $\mathrm{TiI}_{4}$, as in Figure 11 。

The condenser area calculated on the basis of previous experimental 
and a maximum deposit diameter of $3 / 4$ inch; this area corresponds to an over-all heat transfer coefficient of $80 \mathrm{BTU} / \mathrm{hr}-\mathrm{sq} \mathrm{f}_{\mathrm{ft}}{ }^{\circ} \mathrm{F}$, which compares favorably with the range of coefficients, $75-200 \mathrm{BTU} / \mathrm{hr}-\mathrm{sq}$. ft- ${ }^{\circ} \mathrm{F}$, to be expected from heat transfer by free convection from condensing steam to boiling water.

Only. the tubes and parts which contact $\mathrm{TiI}_{4}$ must be made of a resistant metal. The parts in contact with water or steam only may be. made of either stainless steel or ordinary steel.

The heat removal by the small steam condenser to keep the pressure from rising above 60 psia can be controlled by adjusting the coolingwater rate. The condenser is designed for maximum desirable heat removal at a cooling-water temperature of $80^{\circ} \mathrm{F}$ and an assumed over-all heat transfer coefficient of $200 \mathrm{BTU} / \mathrm{sq}$.ft-hr- ${ }^{\circ} \mathrm{F}$; this gives an area of $0.3 \mathrm{ft}^{2}$. The condenser may be made of stainless steel or ordinary steel.

$I_{2}$ Condenser Design

The $I_{2}$ condenser design is shown in Figure 12, Page 43 . It should be a removable water-cooled bayonet tube, because the $I_{2}$ may be easily scraped off after a run. A condensing surface area of 0.4 square feet should be sufficient.

It is suggested that this condenser be made of glass in order to observe the formation of condensate. The removable bayonet tube may be attached by a ground-glass joint lubricated with silicone grease; the condenser may be attached to the trap with a ball joint, and a suitable metal-to-glass seal must be made to the $\mathrm{TiI}_{4}$ condenser.

Reactor Design

The reactor is shown in Figure 10, Page 4\%. The critical parts of the reactor design are to make it vacuum tight, get allow for expansion 


$$
-44^{\circ}
$$

\section{0}

of the hot tube, and make the tube easily accessible for removal. A liquid-tight seal is maintained by a teflon gasket. Teflon chevrons between stainless steel washers packed with some silicone grease will maintain a vacuum seal. Water cooling coils should be used to avoid $\therefore$ overheating the chevrons (obtainable from Raybestos-Manhattan, Inco, Packing Division, Manhattan, Pennsylvania). Concentric screws can independently increase spring pressure on the tantalum tube for film boiling or on the chevron packing. The ends of the reactor may be removed for access to the tube for film boiling. A thermocouple and voltage probe may be put in the holes in the electrodes; they must be sealed in at the electrode ends with a vacuum putty. A Hastelloy C gear pump should be used to circulate $\mathrm{TiI}_{4}$ continuously; the liquid level is exactly maintained by the drain at the appropriate level. Nichrome heating wires and insulation are wrapped around tubing and containers for liquid $\mathrm{TiI}_{4}$ to prevent solidification. $\mathrm{TiI}_{4}$ Reservoir Design

The $\mathrm{TiI}_{4}$ reservoir is shown in Figure 9; Page 46. Nichrome heating coils are used to melt the solid $\mathrm{TiI}_{4}$; the vent should be partially open during heating to prevent build-up of excessive pressure. The melted $\mathrm{TiI}_{4}$ may be started cycling through the reactor and pump by applying inert gas pressure at a vent. 


\section{1}

\section{ACKNOWLEDGMENT}

I wish to thank Professor LeRoy A. Bromley for his suggestions and assistance in formulating the theory and designing the apparatus; I wish to thank Mis. Jane waite for typing the thesis. 


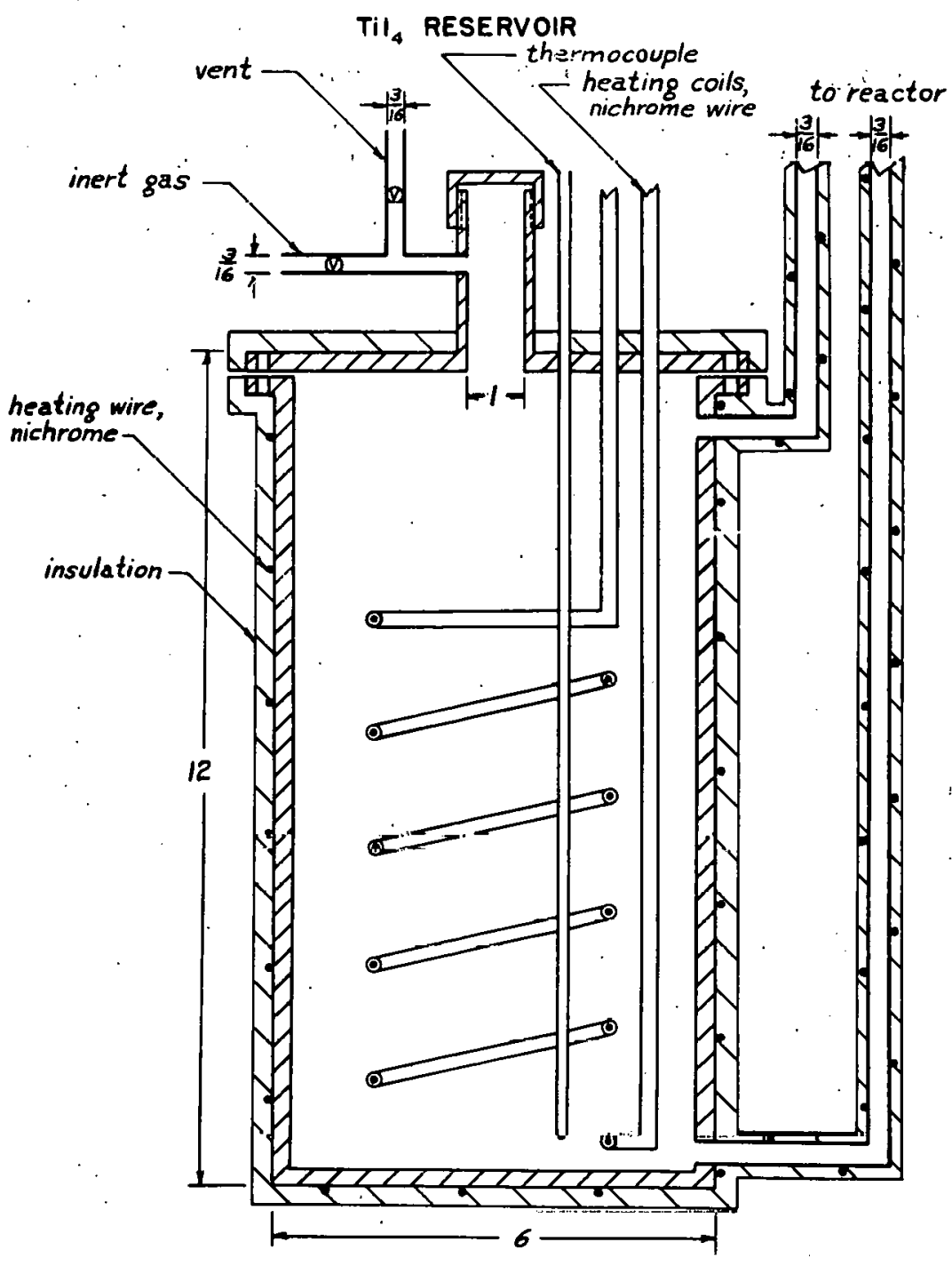

F1g. 9 


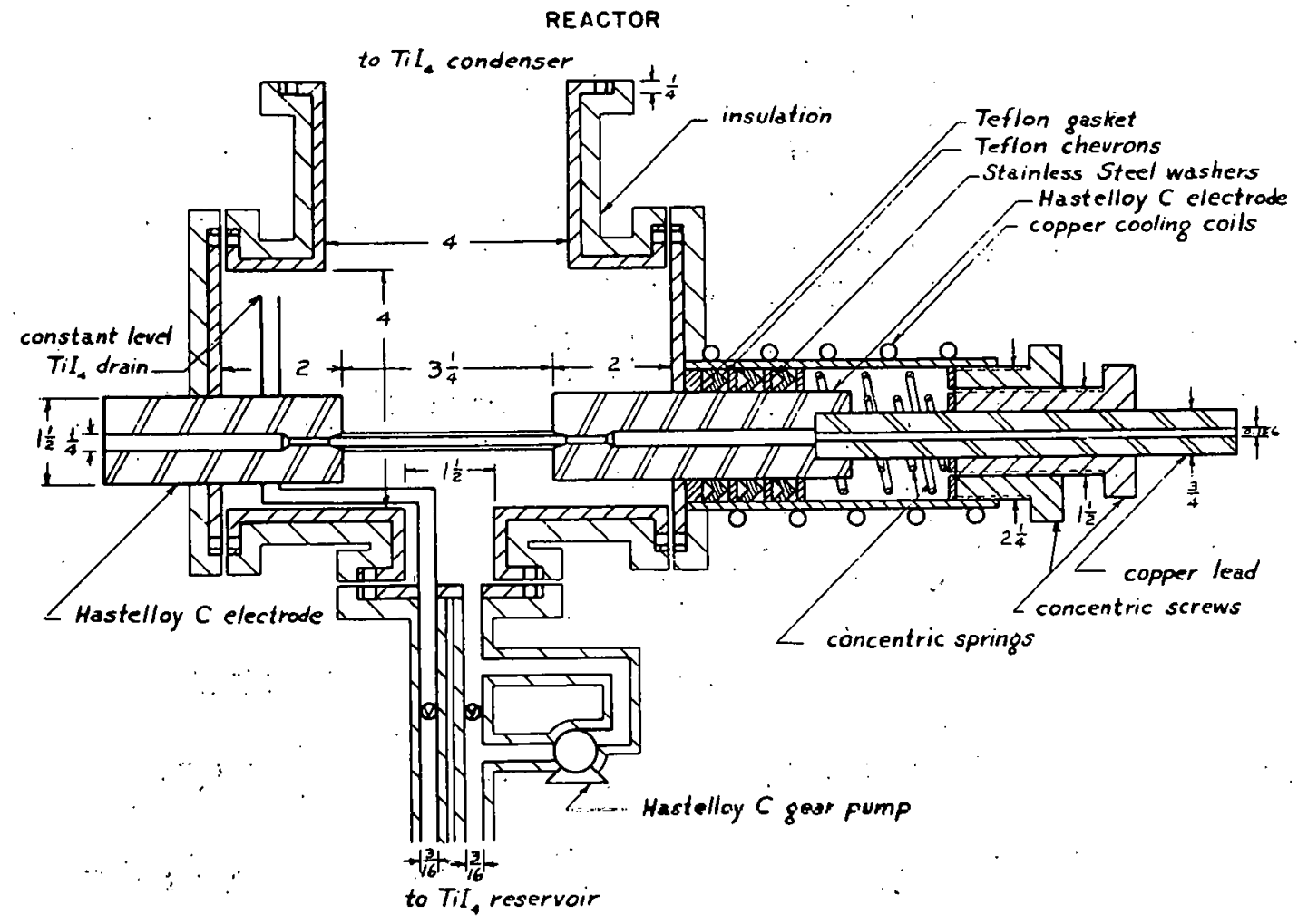

Fig. 10 


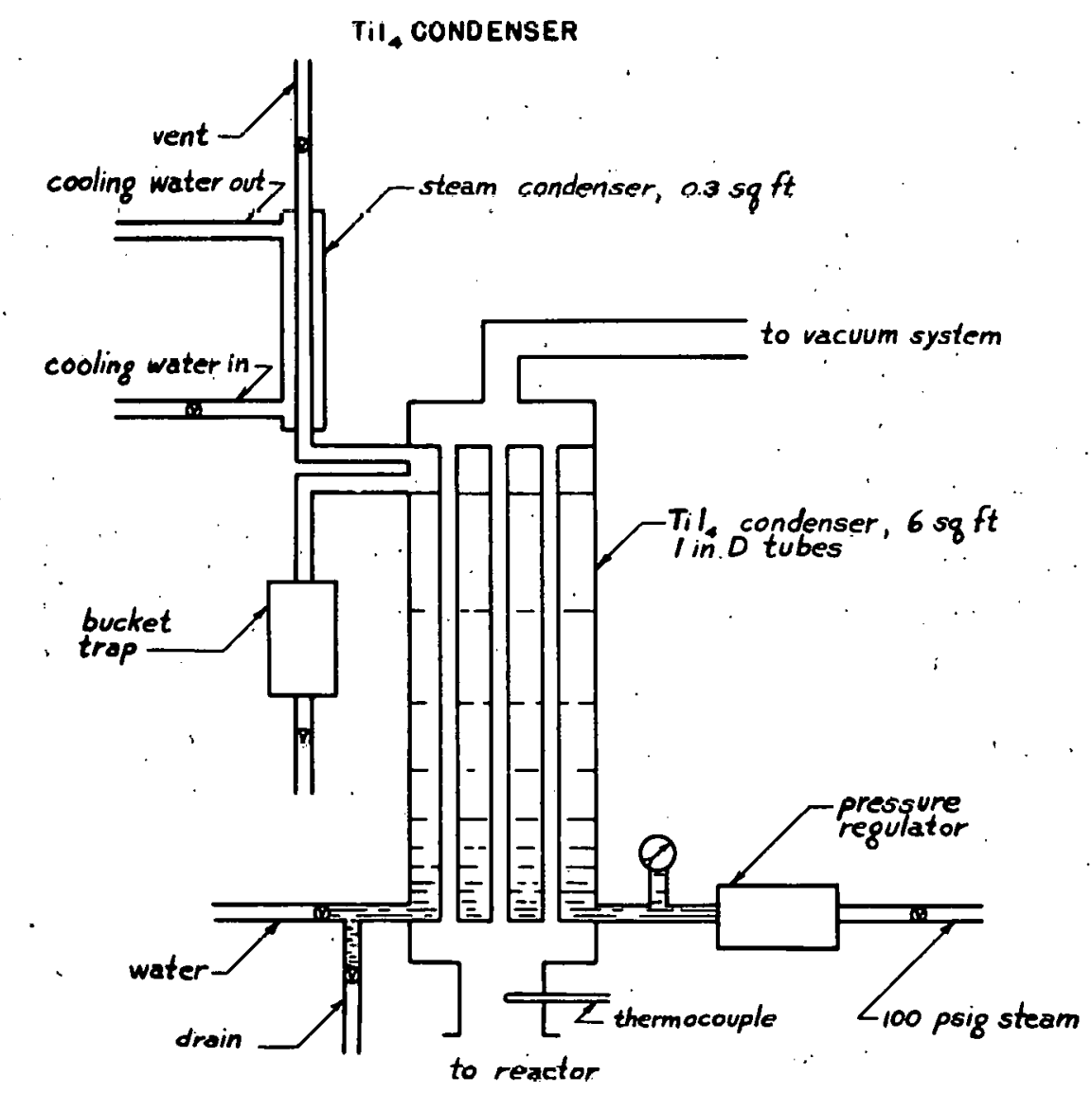

F1g. 11 


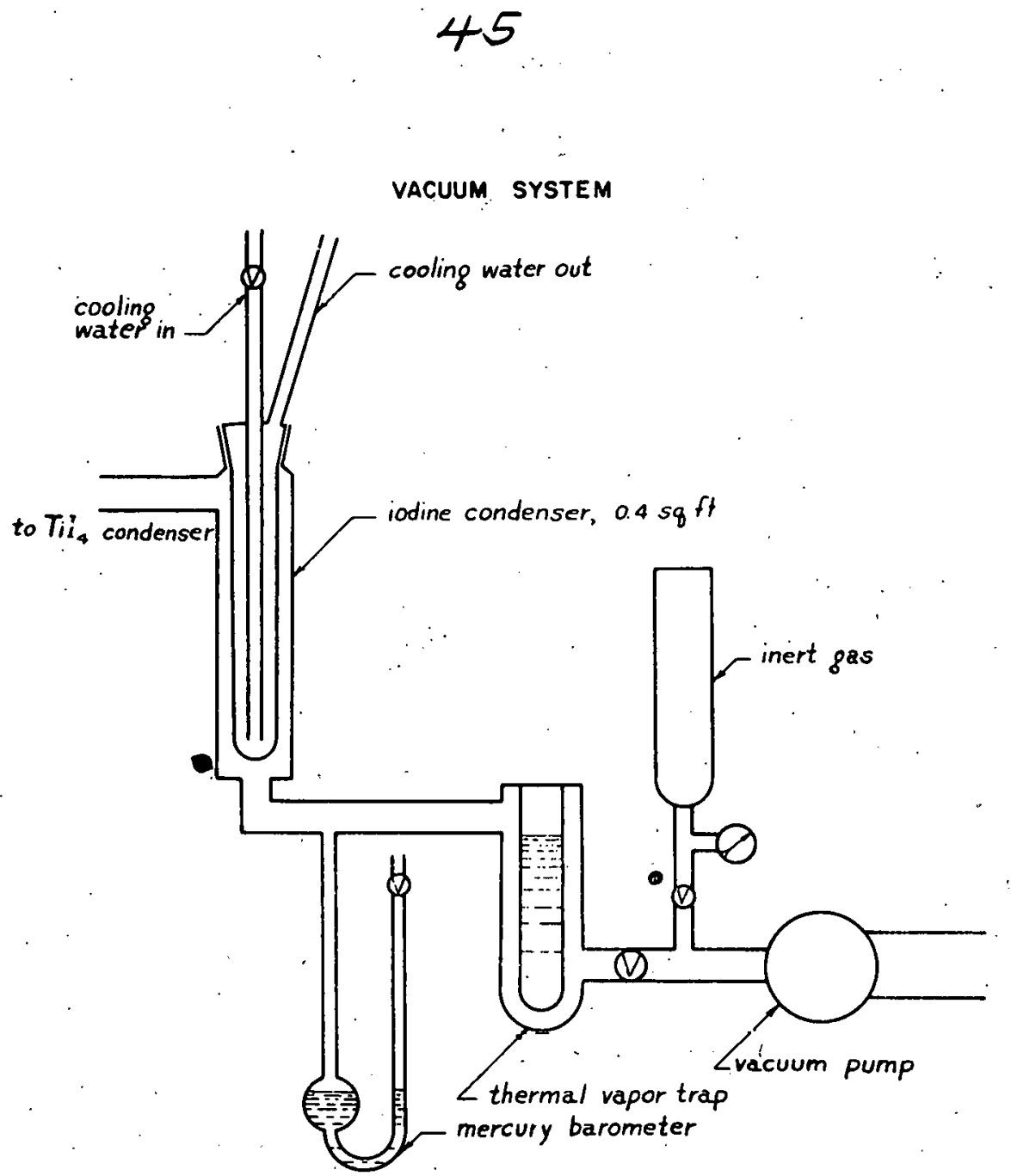

Fig. 12 


\section{Average Deposition Rate Calculation}

An arithmetic average surface area for deposition is assumed.

Then,

$$
\begin{aligned}
\mathbf{r} & =\frac{\pi / 4\left(D_{1}^{2}-D_{0}^{2}\right) I \rho^{\prime}}{\frac{\pi\left(D_{1}+D_{0}\right)}{2}} \\
& =\frac{\left(D_{1}-D_{0}^{\prime}\right) \rho}{2 \theta} \\
& =\frac{\rho t}{\theta}
\end{aligned}
$$

$r=$ depos. $\operatorname{rate}\left(\mathrm{mg} / \mathrm{cm}^{2} \cdot \mathrm{hr}\right)$

$\rho=$ density of titanium $\left(4.5 \times 10^{3} \mathrm{mg} / \mathrm{cm}^{3}\right)$

$t=$ thickness of deposit (cm)

$\theta=$ time of deposition (hours)

$D_{1}, D_{0}=$ final, initial diameter $(\mathrm{cm})$

$\mathrm{I}=$ wire length $(\mathrm{cm})$

\section{Effective Film Thickness Calculation}

The heat transfer coefficient without radiation $h_{c o}$ is given by the following equation: 5

$$
h_{c o}=k / x=0.62
$$$$
\sqrt[4]{\frac{k^{2} \rho^{-}\left(P_{1}-P\right) g \lambda c_{p}}{D \Delta t P x}}
$$

The equation holds for cylindrical surfaces of $\mathrm{D}>0.040^{n}$. The efrective film thickness, $x$, may be calculated if the properties of $\mathrm{THI}_{4}$ vapor and conditions are known. At $1600^{\circ} \mathrm{C}$,

$$
g=4.17 \times 10^{8} \mathrm{ft} / \mathrm{hr}^{2}
$$




$$
\begin{aligned}
& t_{1}=160^{\circ} \mathrm{C} \text { for } 6 \mathrm{~mm} \text { Hg pressure } \\
& D=0.040 / 12=0.00334 \mathrm{ft} .
\end{aligned}
$$

$$
\begin{aligned}
C_{p}=C_{v}+R & =\operatorname{trans} E+\operatorname{rot} E+\operatorname{vibr} E+R \\
& =3 / 2 R+3 / 2 R+(3 n-6) R(\operatorname{Max})+R \\
& =26 \mathrm{BTU} / \mathrm{lb}-\operatorname{mole}{ }^{\circ} \mathrm{F}=0.0467 \mathrm{BTU} / \mathrm{lb}-{ }^{\circ} \mathrm{F}
\end{aligned}
$$

where maximum vibr. $E$ was assumed

$$
\begin{aligned}
P_{1} & =200 \mathrm{lb} / \mathrm{ft}^{3} \text { by estimation } \\
& =\frac{(6+3) \times 556}{998.9\left(\frac{1600-160}{2}+160+273\right)}:=4.3 \times 10^{-3} \cdot 1 \mathrm{~b} / \mathrm{ft}^{3}
\end{aligned}
$$

where a liquid head of $3 \mathrm{~mm} \mathrm{Hg}$ was assumed due to immersion of the wire in the liquid.

$\mu=0.075 \mathrm{lb} / \mathrm{hr}-\mathrm{ft}$ estimation ${ }^{16}$.

$\operatorname{Pr}=0.85$ assumption, since $\operatorname{Pr}$ is nearly constant at this value. $\mathrm{k}=\frac{\mathrm{C}_{\mathrm{p}} \mu}{\mathrm{Pr}}=\frac{0.0467 \times 0.075}{0.85}=0.004 \mathrm{BTU} / \mathrm{hr}-\mathrm{ft}-{ }^{\circ} \mathrm{F}$.

$\lambda=45.5 \mathrm{BTU} / \mathrm{lb}$ measurement ${ }^{2}$

$\lambda^{\prime}=45.5+0.0467\left(\frac{1600-160}{2}\right) \quad 1.8=105 \mathrm{BTU} / 1 \mathrm{~b}$ definition ${ }^{5}$ $x=\frac{2.54 \times 12 \times 0.0047}{0.62} \sqrt[4]{\frac{0.00334(1600-160) 1.8 \times 0.85}{(0.0041)^{2} \times 4.3 \times 10^{-3} \times 200 \times 4.17 \times 10^{8}}}$ $\times 105 \times 0.0467$

$=0.025 \mathrm{~cm}$ at $1600^{\circ} \mathrm{C}$

By similar reasoning,

$\mathrm{x}=0.0,20 \mathrm{~cm}$ at $1100^{\circ} \mathrm{C}$ 


\section{8}

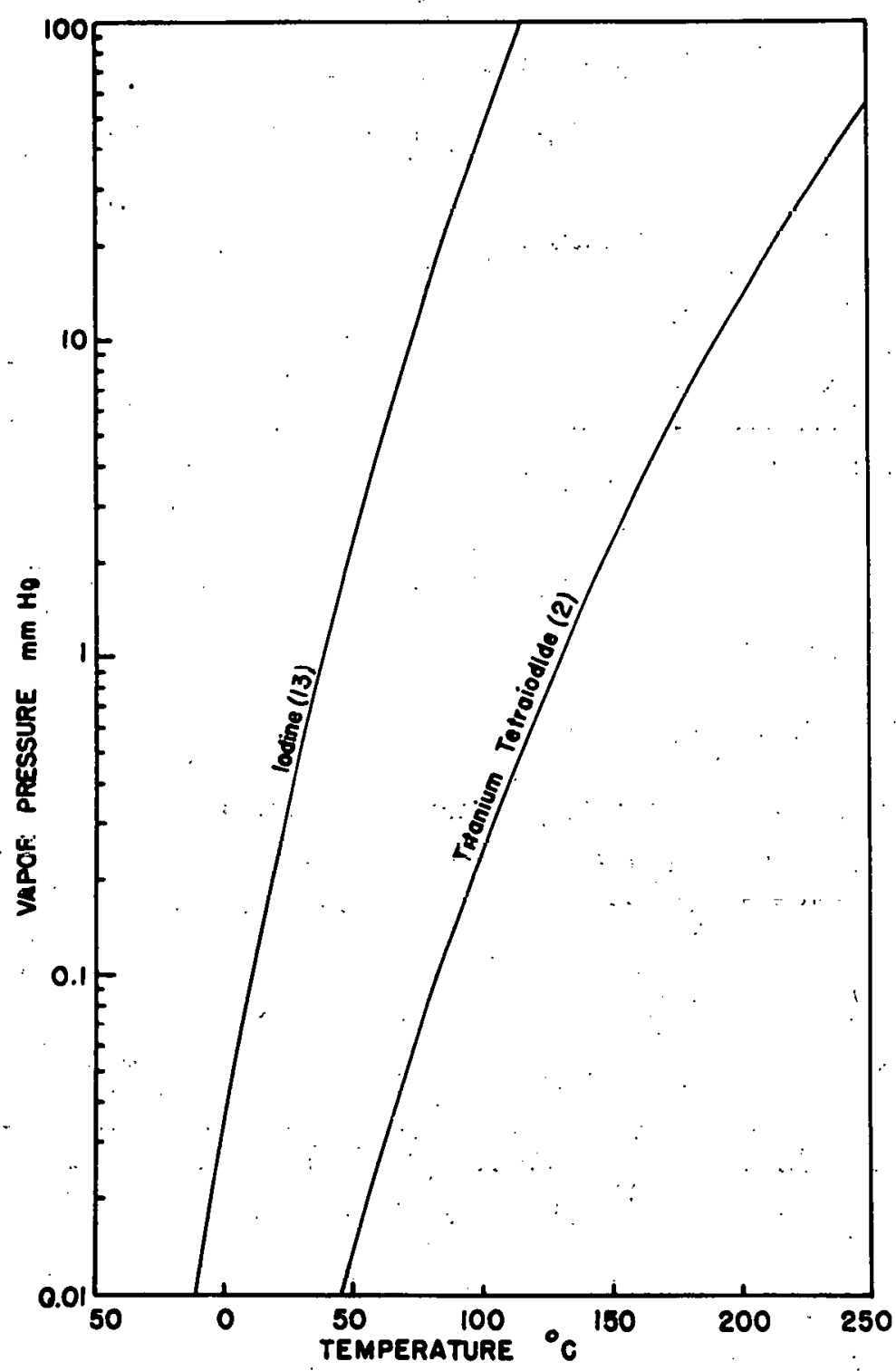

F1g. 13

$23 \cdot 50$ 
49

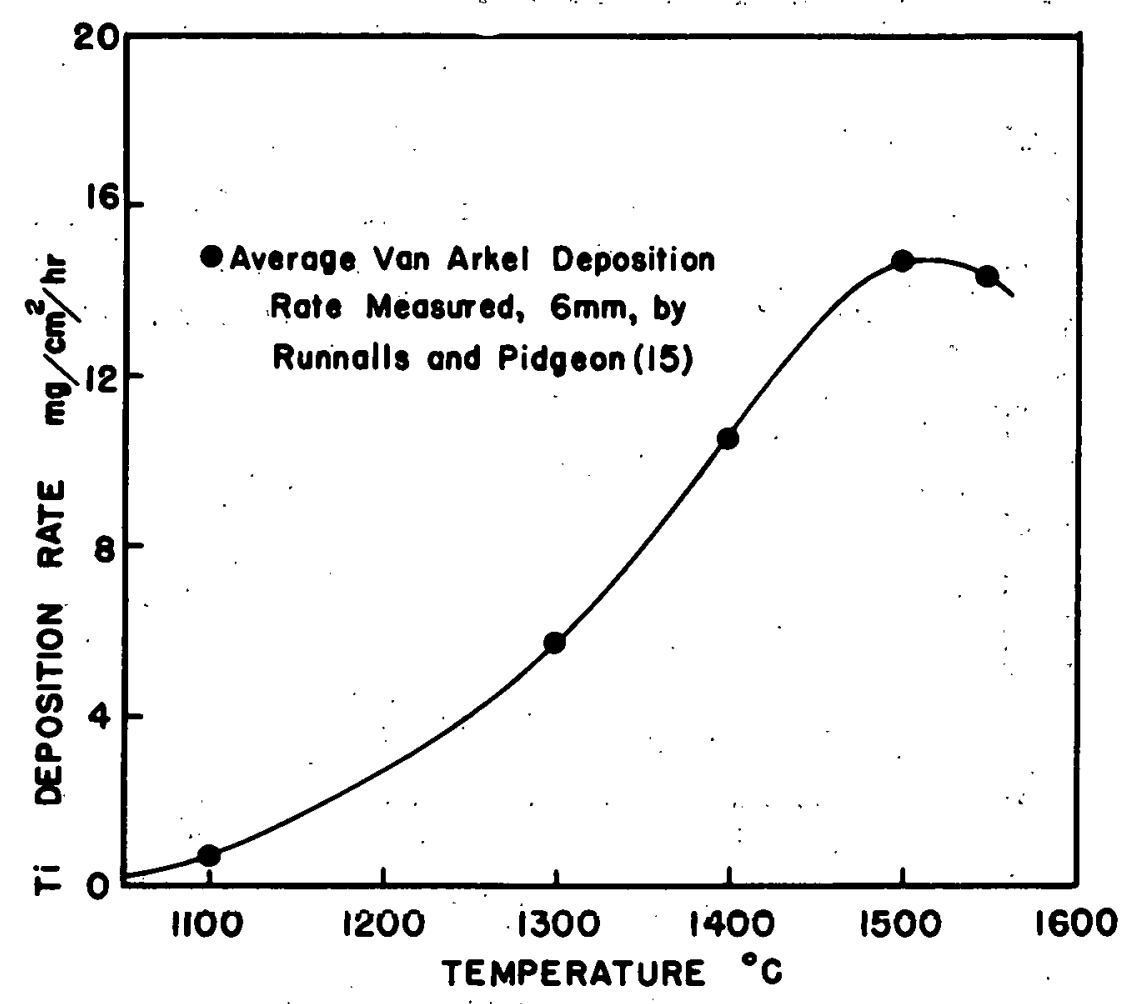

F18. 14 
$-54-$

50

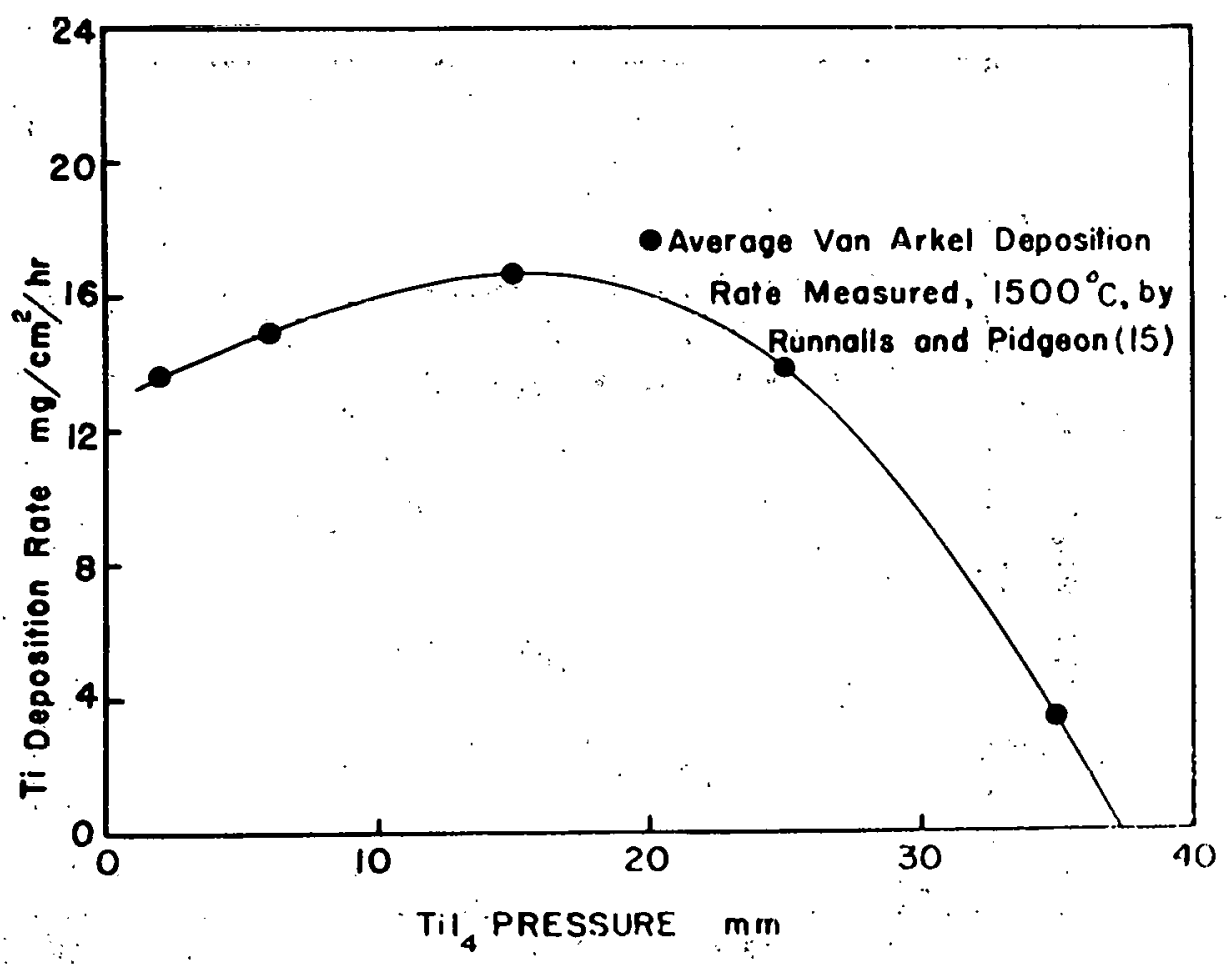

F1g. 15 


\section{$-55$ \\ 5. \\ IX。 BIBLIOGRAPHY}

I. A.E. VanArkel and $J_{0} H_{0}$ deBoer, U.S. Patent 1,671,213 (1928).

2. J. M. Blocher and I. E. Campbe1I, J.Am。 Chem。 Soc. 69, 2100-101 (1947)。

3. J. M. Blocher and I. E. Campbell, J. Am. Chem. Soc. ZI, 4040 (1949).

4. W. B. Blumenthal and H. Smith, Ind. Eng. Chem。 42, 249-5I (1950)。

5. L. A. Bromley, Chem, Eng. Prog. 46, 221-27 (May, 1950)。

6. J. D. Fast, Rec。trav。 chim。 58, 174-80 (1939).

7. J. D. Fast, Z. anorg。 u allgem。Chem。 148, 345 (1925)。

8. W. Gonser, et al॰, Battelle Memorial Institute Report 523 (March, 1951)。

9. P. Hautefeuille, Compt. Rend . 27, 151 (1863)。

10. L. Hoch and W. Z. Knauff, $Z_{0}$ anorg. u allgemo Chem. 228, 204-8 (1936)

11. H. Moissan; Compt. Rend. 120, 290 (1895)。

12. P.Pascal, "Traite de Chimie Minerale," Vol。 V, Page 566, Paris, Masson et Cie (1932).

13. J. H. Perry॰. "Chemical Engineers" Handbook" Page 151 (1950)。

140 L. L. Quill. "Chemistry and Metallurgy of Miscellaneous Materials: Thermodynamics" (1950).

15. 0. J. C. Runnalls and I. M. Pidgeon, J. of Metals 4, 843-47 (Aug., 1952)。 16. c. R。 Wilke, Ind. Eng.Chem。 43, 164I (July, 1951)。 